\title{
Root and stem rot, and wilting of olive tree caused by Dematophora necatrix and associated with Emmia lacerata in Central Italy
}

\author{
Valeria Fusco • Vittorio Pasciuta • Valentina Lumia • Antonio Matere • Valerio \\ Battaglia • Giorgia Bertinelli • Domenico Sansone - Angela Brunetti • Massimo Pilotti
}

Accepted: 31 December 2021 / Published online: 23 January 2022

(C) Koninklijke Nederlandse Planteziektenkundige Vereniging 2022
Irpicaceae, which is the agent of white rot on dead woody substrates. To our knowledge, this is the first time that E. lacerata has been reported in Italy and worldwide on olive trees. Inoculation of Favolosa' trees revealed that it colonizes the xylem without causing visible alterations. The possible role of E. lacerata in the olive tree-D. necatrix pathosystem is discussed.

Keywords Olive tree $\cdot$ Favolosa $\cdot$ Dematophora necatrix $\cdot$ Emmia lacerata $\cdot$ Stem rot and wilting . (potential) fungicides

\section{Introduction}

The olive tree (Olea europea L.) was a key crop in early human settlements in the Mediterranean. According to Besnard et al. (2013), its primary origin from the oleaster dates back to $6000-8000$ years ago in the northeastern Levant territory of the Mediterranean basin, approximately in the area close to the Syria-Turkish border. Today, the olive tree is still an important crop in the Mediterranean Basin, where it yields the highest production of oil and table olives worldwide (European Commission, 2021). The beneficial health effects on humans of the oil and leaves have been known since ancient times and investigated intensively in recent years (Rigacci \& Stefani, 2016; Özcan \& Matthäus, 2017).

The Italian olive germplasm is generally suitable for both traditional and intensive cultivation (maximum of

\footnotetext{
V. Fusco · V. Pasciuta · V. Lumia · A. Matere •

V. Battaglia · G. Bertinelli - D. Sansone - A. Brunetti ·

M. Pilotti $(\square)$

Research Center for Plant Protection and Certification

(CREA-DC), Council for Agricultural Research and Economics,

Via C. G. Bertero 22, 00156 Rome, Italy

e-mail: massimo.pilotti@crea.gov.it
} 
400 trees/ha) (Vitagliano \& Sebastiani, 2003). A Super High Density (SHD) cultivation system with up to more than 2000 trees/ha has become increasingly common. SHD is based on a complex farming management aimed at increasing production and thus responding to a more competitive market. Given the high density, SHD requires genotypes with a compact form and a reduced growth. Thus, few of the cultivars on the market are suited for this cultivation system (Farinelli \& Tombesi, 2015; Stillitano et al., 2016; Díez et al., 2016; Mairech et al., 2020). In addition to the Spanish cultivars, the Italian FS-17 ('Favolosa'), a seedling from 'Leccino' (Fontanazza et al., 1998), has recently begun to be used in Italy in SHD groves.

Many diseases can damage olive trees by affecting woody organs - the stem and branches - and as a consequence, the viability of the whole tree. The soil borne and vascular fungus Verticillium dahliae (Kleb.), which is the agent of verticillium wilt, is a major threat to olive trees because of the potential for rapid spread, the heavy impact on plant viability once the infection has settled, and difficulties in applying effective disease management strategies. Wood discolouration patterns are typically associated with verticillium wilt (LópezEscudero \& Mercado-Blanco, 2011; Jimenez-Diaz et al., 2012).

A previously unknown disease, the Olive Quick Decline Syndrome (OQDS), has appeared in the Salento peninsula (Puglia, south-east Italy) causing unprecedented damage in the olive groves. Xylella fastidiosa subsp. pauca (Schaad, Postnikova, Lacy, Fatmic \& Chang) (Xfp), a quarantine pest which is the causal agent of OQDS. Xfp typically inhabits the xylem, where it multiplies and occludes the vessels, which hampers normal water conduction resulting in rapid canopy scorching and death of the trees (Frisullo et al., 2014; Jeger et al., 2018). The dramatic outbreak of OQDS led to the EU and the Italian Ministry of Agriculture, Food and Forestry dictating the measures for eradication and prevention.

Further complicating the sanitary situation of the olive has been the emergence of additional decline syndromes, not attributable to Xfp or $V$. dahliae, and characterised by the discolouration and necrosis of the xylem and bark and the loss of viability of portions or the whole canopy. These syndromes have been associated with a complex mycobiota in which some fungal taxa-Pleurostomophora richardsiae, Botryosphaeraceae, Phaeoacremonium spp.,
Hymenomycetes - seemed to play major roles (Carlucci et al., 2013a; Úrbez-Torres et al., 2013; Carlucci et al., 2015; Moral et al., 2017).

Consequently, the focus on olive tree diseases has increased amongst governments, plant protection organizations and scientific institutions, and also hobby farmers.

Following a request by an olive grower, we surveyed an SHD orchard with young olive trees cv 'Favolosa' located in the Marche region (central Italy) and affected by a sudden wilting leading to the death of the trees. The urgent need to assess the presence/absence of Xfp, and the fact that 'Favolosa' is currently under study by scientific institutions due to its promising resistance level to Xfp (Boscia et al., 2017; Jeger et al., 2018)prompted us to investigate the nature of the syndrome.

In this article, we describe our aetiological investigations into the disease. While excluding the presence of Xfp and V. dahliae, we identified Dematophora necatrix (Berl. ex Prill.) as the agent of the disease. We also revealed the presence of an additional fungal species which was strictly associated with olive plants in the diseased grove. The fungus was identified as Emmia lacerata (N. Maek., Suhara \& R. Kondo) F. Wu, Jia J. Chen \& Y.C. Dai, and is reported in olive trees here for the first time, in Italy and worldwide. To enable olive growers to control the disease from the onset, we also assessed the sensitivity of $D$. necatrix to systemic fungicides and other active substances in in vitro assays, and then tested three of them in curative and preventive inoculation plant trials.

\section{Materials and methods}

Symptom survey, sample collection, isolations and plant material

Our survey was carried out in September 2018 in an olive orchard of irrigated two-year-old cv Favolosa trees at a spacing of $4 \times 2.2 \mathrm{~m}$, and located in the Marche region, central Italy. Planting had been established in April 2017 with 320 less than one year old trees, and soon after removing an old plum orchard.

Alterations of internal tissue were explored by sectioning the stem. Ten diseased trees in which wilting was progressing were sampled. Isolations were performed from the discoloured/necrotic wood matching fresh 
reaction zones. Representative zones were sampled from the roots and stem of each tree and pooled. Healthy-looking wood was also sampled from: i) four healthy-looking trees in the grove; ii) from 10 healthylooking Favolosa' plants, among those that we purchased from a commercial nursery in order to perform pathogenicity tests; iii) and from five mature trees (twoyear old branches) grown in the garden of our Research Center, CREA-DC, in Rome.

Small fragments of the wood samples were rapidly flamed and plated on two types of cultural media: potato dextrose agar (PDA) (Oxoid, Thermo Fisher Scientific, Waltham, Massachusetts USA) with $300 \mathrm{mg} \mathrm{L}^{-1}$ streptomycin with or without benomyl [Methyl 1-(butylcarbamoyl)-2-benzimidazolecarbamate] (Merck KGaA, Darmstadt, Germany). Thirty-six fragments were plated on each medium, thus 72 for each sampletree. All plates were incubated at $25{ }^{\circ} \mathrm{C}$, in the dark. Fungal colonies were selected by transferring in purity on fresh PDA plates.

Favolosa', Leccino' and Ogliarola' were used for the inoculation trials. Favolosa' plants were supplied by Vivaio Elaia (Perugia, Umbria, Italy), Leccino' by Spoolivi - Società Pesciatina d'Olivicoltura (Pescia, Pistoia, Tuscany, Italy), and Ogliarola' by Vivai De Nicolo (Terlizzi, Bari, Apulia, Italy). All plants had been transplanted into 23-1 pots, except for Favolosa' which was grown in 6.5-1 pots due to its small size and slow growth rate. The pot substrate was Radicom (Vigorplant, Lodi, Italy), containing a mixture of peat moss, black peat, marsh peat, and vegetable compost. Humus was present in this substrate in the form of humic and fulvic acids with a water $\mathrm{pH}$ of 6-6.5.

Morphological and cultural characteristics of the isolated fungi

Fungal identification was carried out by observing the morphological and structural features of the fungi, under a stereo microscope and a light microscope (Leica DM6B).

To assess the optimum, minimum, and maximum temperatures for growth of $D$. necatrix, the growth rate of three isolates was assessed at temperatures from 5 to $40{ }^{\circ} \mathrm{C}$ with a step-size of 5 , in the dark. For each temperature, five PDA plates were inoculated with a fungal plug $9 \mathrm{~mm}$ in diameter taken from an actively growing colony. Two diameters for each colony, at right angles to each other, were measured after the colony had covered roughly $70 \%$ of the surface for fast-growing rates $\left(15,20,25^{\circ} \mathrm{C}\right)$, or after five days for slow growth or growth blockage $\left(5,30,35,40^{\circ} \mathrm{C}\right)$, and 20 days at $10{ }^{\circ} \mathrm{C}$. If no growth occurred at the highest temperatures tested, the viability of the mycelium was tested by transferring the inoculated plates at $25^{\circ} \mathrm{C}$. Growth data were used to infer the medium daily growth. Growth of the three isolates was also tested in a growth chamber at $25{ }^{\circ} \mathrm{C}$ under continuous led light (500 lx) (KW Apparecchi Scientifici, Monteriggioni, Siena, Italy) in parallel with the test conducted at $25^{\circ} \mathrm{C}$ in the dark.

Molecular detections, DNA sequencing and phylogeny-based identification

All samples were tested with well-known Xfp and $V$. dahliae-targeted real-time PCR procedures (Harper et al., 2010; Bilodeau et al., 2012; EPPO 2019).

The complete ITS region was amplified and sequenced for the identification of all fungal isolates. Additional DNA loci were amplified and sequenced to infer multi-locus phylogenies for species determination of the most relevant fungi: the nuclear Large SubUnit rDNA (nLSU), beta-tubulin 2 (TUB2) and the second largest subunit of the DNA-directed RNA Polymerase II (RPB2) were amplified and sequenced in three representative isolates of $D$. necatrix. nLSU was sequenced in all isolates for which ITS sequencing suggested an identification with $E$. lacerata. Details on fungal gDNA extraction, primers, reaction assembly, thermal cycling of the amplifications and the analysis in agarose gel electrophoresis, are reported in Online Resource 1.

PCR amplicons were directly sequenced in both directions by Sanger technology (Bio-Fab research s.r.l., Rome, Italy). Sequences newly generated in this study were compared with GenBank accessions using the NCBI BLASTN suite (https://blast.ncbi.nlm.nih. gov/Blast.cgi?LINK_LOC=blasthome\&PAGE_ TYPE=BlastSearch\&PROGRAM=blastn). They were deposited in the NCBI GenBank (Table 1). All sequences and their accession numbers are also reported in Online Resource 1.

Phylogenetic trees of Xylariaceae and of the Phlebioid clade were inferred to confirm or establish the specific nature of $D$. necatrix and E. lacerata-like isolates, respectively. Combined multiloci datasets were used as input for the analyses: [ITS + nLSU + TUB2 + RPB2] for Xylariaceae, and [ITS $+\mathrm{nLSU}]$ for the Phlebioid clade. [ITS $+\mathrm{nLSU}]$ has been used by several authors for 
Table 1 Fungi isolated in this study from diseased and asymptomatic olive saplings and sequences newly generated for their identification and the phylogenetic analyses

\begin{tabular}{|c|c|c|c|c|c|c|}
\hline \multirow[t]{2}{*}{ Voucher specimen } & \multirow[t]{2}{*}{ Sapling } & \multirow[t]{2}{*}{ Identification } & \multicolumn{4}{|l|}{ Acc. NOs } \\
\hline & & & ITS & nLSU & TUB2 & RPB2 \\
\hline CREA-DC TPR OL.81 & Diseased 1 & Dematophora necatrix & MW677457 & & & \\
\hline CREA-DC TPR OL.107 & Diseased 1 & Emmia lacerata & MW677458 & MW714614 & & \\
\hline CREA-DC TPR OL.108 & Diseased 1 & Phlebia acerina & MW677459 & & & \\
\hline CREA-DC TPR OL.82 & Diseased 2 & Dematophora necatrix & MW677460 & MW714611 & MZ325498 & MZ325501 \\
\hline CREA-DC TPR OL.109 & Diseased 2 & Emmia lacerata & MW677461 & MW714615 & & \\
\hline CREA-DC TPR OL.110 & Diseased 2 & Trametes versicolor & MW677462 & & & \\
\hline CREA-DC TPR OL.111 & Diseased 2 & Phlebia acerina & MW677463 & & & \\
\hline CREA-DC TPR OL.83 & Diseased 3 & Dematophora necatrix & MW677464 & & & \\
\hline CREA-DC TPR OL.112 & Diseased 3 & Emmia lacerata & MW677465 & MW714616 & & \\
\hline CREA-DC TPR OL.113 & Diseased 3 & Phlebia acerina & MW677466 & & & \\
\hline CREA-DC TPR OL.114 & Diseased 3 & Phomopsis sp. & MW677467 & & & \\
\hline CREA-DC TPR OL.115 & Diseased 3 & Fusarium sp. & MW677468 & & & \\
\hline CREA-DC TPR OL.85 & Diseased 4 & Dematophora necatrix & MW677469 & & & \\
\hline CREA-DC TPR OL.116 & Diseased 4 & Alternaria sp. & MW677470 & & & \\
\hline CREA-DC TPR OL.117 & Diseased 4 & Porostereum spadiceum & MW677471 & & & \\
\hline CREA-DC TPR OL.118 & Diseased 4 & Emmia lacerata & MW677472 & MW714617 & & \\
\hline CREA-DC TPR OL.86 & Diseased 5 & Dematophora necatrix & MW677473 & MW714612 & MZ325499 & MZ325502 \\
\hline CREA-DC TPR OL.119 & Diseased 5 & Emmia lacerata & MW677474 & MW714618 & & \\
\hline CREA-DC TPR OL.120 & Diseased 5 & Agaricomycetes & MW677475 & & & \\
\hline CREA-DC TPR OL.87 & Diseased 6 & Dematophora necatrix & MW677476 & & & \\
\hline CREA-DC TPR OL.122 & Diseased 6 & Emmia lacerata & MW677477 & MW714619 & & \\
\hline CREA-DC TPR OL. 88 & Diseased 7 & Dematophora necatrix & MW677478 & & & \\
\hline CREA-DC TPR OL.124 & Diseased 7 & Emmia lacerata & MW677479 & MW714620 & & \\
\hline CREA-DC TPR OL.126 & Diseased 8 & Emmia lacerata & MW677480 & MW714621 & & \\
\hline CREA-DC TPR OL.89 & Diseased 9 & Dematophora necatrix & MW677481 & MW714613 & MZ325500 & MZ325503 \\
\hline CREA-DC TPR OL.128 & Diseased 9 & Emmia lacerata & MW677482 & MW714622 & & \\
\hline CREA-DC TPR OL.129 & Diseased 9 & Alternaria sp. & MW677483 & & & \\
\hline CREA-DC TPR OL.90 & Diseased 10 & Dematophora necatrix & MW677484 & & & \\
\hline CREA-DC TPR OL.91 & Diseased 10 & Fusarium sp. & MW677485 & & & \\
\hline CREA-DC TPR OL.130 & Diseased 10 & Fusarium sp. & MW677486 & & & \\
\hline CREA-DC TPR OL.131 & Diseased 10 & Emmia lacerata & MW677487 & MW714623 & & \\
\hline CREA-DC TPR OL.132 & Diseased 10 & Phlebia acerina & MW677488 & & & \\
\hline CREA-DC TPR OL.177 & Asymptomatic 1 & Lentinus tigrinus & MW677489 & & & \\
\hline CREA-DC TPR OL.178 & Asymptomatic 1 & Peniophora rufomarginata & MW677490 & & & \\
\hline CREA-DC TPR OL.179 & Asymptomatic 1 & Alternaria sp. & MW677491 & & & \\
\hline CREA-DC TPR OL.133 & Asymptomatic 2 & Emmia lacerata & MW677492 & MW714624 & & \\
\hline CREA-DC TPR OL.135 & Asymptomatic 2 & Bipolaris sp. & MW677493 & & & \\
\hline CREA-DC TPR OL.136 & Asymptomatic 3 & Emmia lacerata & MW677494 & MW714625 & & \\
\hline CREA-DC TPR OL.137 & Asymptomatic 3 & Alternaria sp. & MW677495 & & & \\
\hline CREA-DC TPR OL.139 & Asymptomatic 4 & Emmia lacerata & MW677496 & MW714626 & & \\
\hline CREA-DC TPR OL.141 & Asymptomatic 4 & Phlebia acerina & MW677497 & & & \\
\hline CREA-DC TPR OL.142 & Asymptomatic 4 & Agaricomycetes & MW677457 & & & \\
\hline
\end{tabular}


taxonomical assignments within the Irpicaceae/Ceriporia/ Emmia(Zmitrovich \& Malysheva, 2014; Jia et al., 2014; Spirin et al., 2016; Permpornsakul et al., 2016; Yuan et al., 2017; Wulandari et al., 2018; Chen et al., 2020). The phylogenetic analyses involved three representative isolates of $D$. necatrix and all 13 E. lacerata-like isolates obtained in this study. Phylogeny of Wittstein et al. (2020) and Chen et al. (2020) served us as a model to construct the phylogeny of Xylariaceae and of the Phlebioid clade, respectively. Reference sequences for Xylariaceae were selected among those used by Wittstein et al. (2020) and others collected in NCBI (Online Resource 2). Reference sequences of the phlebioid strains were chosen from those used by Chen et al. (2020), Wulandari et al. (2018), Yuan et al. (2017) and Jia et al. (2014) (Online Resource 3). Outgroups for Xylariaceae were Hypoxylon fragiforme (Pers.: Fr.) J. Kickx f. and Graphostroma platystomum(Schwein) Piroz. representing Hypoxylaceae and Graphostromataceae, respectively, which are two additional families in the Xylariales. Outgroups for the Phlebioid clade were Verticillium dahliae Kleb. and Pleurostoma richardsiae (Nannf.) Reblova \& Jaklitsch, as Ascomycota representatives. Sequences of each locus were aligned with MAFFT on the EMBL-EBI server (htpps://www.ebi.ac.uk), then the alignments were concatenated in MEGA X (Kumar et al., 2018). The evolutionary history was inferred using the Maximum Likelihood method and General Time Reversible model (Nei \& Kumar, 2000). Bootstrap values were calculated from 1000 replicates. Initial tree(s) for the heuristic search were obtained automatically by applying Neighbor-Join and BioNJ algorithms to a matrix of pairwise distances estimated using the Maximum Composite Likelihood approach, and then selecting the topology with superior log likelihood value. Evolutionary analyses were conducted in MEGA X (Kumar et al., 2018).

The alignment datasets for phylogenetic trees have been submitted in TreeBASE and can be accessed at: http://purl.org/phylo/treebase/phylows/study/TB2 :S28813 $\mathrm{x}$-access-code $=2265 \mathrm{a} 164 \mathrm{~b} 135 \mathrm{~b} 62 \mathrm{~b} 0$ bcb5586898dab7d\&format=html

Inoculation trials to assess fungal pathogenicity

Inoculation trials were carried out to assess the pathogenicity of $D$. necatrix isolate CREA-DC TPR OL.82. As E. lacerata was consistently isolated from both symptomatic and healthy-looking olive trees, we also set up an inoculation trial with isolates of this species (CREA-DC TPR OL.109, 126, 133, 139).
Favolosa' plants were about $30-35 \mathrm{~cm}$ in height at the time of the first-round of inoculation with $D$. necatrix, and $50-60 \mathrm{~cm}$ in the second-round. Plants were $70-80 \mathrm{~cm}$ when they were inoculated with E. lacerata. The other cultivars inoculated with $D$. necatrix were $140-150 \mathrm{~cm}$, and $180-190 \mathrm{~cm}$ in height at the spring and autumn inoculations, respectively. For details see Table 2.

The inoculations were performed as follows. Rectangular PDA-mycelium plugs $[10 \times 3-4 \mathrm{~mm}$ sized (Favolosa') and $15 \times 8-10 \mathrm{~mm}$ (the other cultivars)] were cut from actively growing colonies and used to inoculate the stem at a height of 8-10 cm (Favolosa') and $15 \mathrm{~cm}$ (the other cultivars). Specifically, the mycelial plugs were placed on similarly sized wounds, i.e., on the xylem surface which had been exposed by cutting the bark top-down with a razor blade through the cambium. The bark strip was then gently set on the plug. The inoculation point was covered with a cotton disk wetted with $3 \mathrm{ml}$ of sterile water, and wrapped with a sterile strip of aluminum foil, which was taped to the stem at the top and bottom edges. The cover was removed after 25-30 days.

As natural symptoms occurred more in the buried part of the stem, we tried to re-create this field condition in the inoculation tests to verify whether symptom development had been facilitated in the field by burying the basal part of the stem. We adapted the marcotting grafting technique and carried out some inoculation treatments using the following protocol: after the inoculation coverage had been removed, an opaque plastic sheet was wrapped around the stem at the inoculation point. The lower end of the plastic sheet was gathered and tied securely against the stem, about $8 \mathrm{~cm}$ (Leccino') and $4 \mathrm{~cm}$ (Favolosa') under the inoculation point. Laterally the edges of the sheets were stapled together. The top ( $8 \mathrm{~cm}$ and $4 \mathrm{~cm}$ above the inoculation point in Leccino' and Favolosa', respectively) was left open and a moistened substrate, previously autoclaved at $121{ }^{\circ} \mathrm{C}$ for $20 \mathrm{~min}$., was inserted gradually to fill the empty space inside the wrapping. The substrate was kept moderately moistened throughout the entire course of the trials. An image of the marcottage is reported in Online Resource 4. See Table 2 for the timing of the marcottage application. The hypothesis that marcottage might enhance symptom expression was formulated when the first inoculation trials were ongoing. Thus, in these cases marcotting was applied somewhat late with respect to the time of inoculation coverage removal (I and II trial on Leccino', Table 2). On the other hand, for the II trials on Favolosa', marcottage was applied soon after the inoculation coverage had been removed, in accordance with the protocol. 
Table 2 Trials to assess the pathogenicity of Dematophora necatrix and Emmia lacerata on different olive cultivars. Five (Leccino)/ten (Favolosa) sterile PDA-inoculated plants were used as control in each inoculation round and for each modality

\begin{tabular}{llllll}
\hline $\begin{array}{l}\text { Olive } \\
\text { cultivar }\end{array}$ & $\begin{array}{l}\text { Age in months } \\
\text { (replications) }\end{array}$ & $\begin{array}{l}\text { Stem diameter at the } \\
\text { inoculation point }(\mathrm{cm})\end{array}$ & $\begin{array}{l}\text { Date of } \\
\text { inoculation }\end{array}$ & $\begin{array}{l}\text { Date of marcottage) } \\
\text { (time span in days) })^{1,2}\end{array}$ & $\begin{array}{l}\text { Date of destructive recording } \\
\text { or of complete death (time } \\
\text { span of the trial in days) }\end{array}$ \\
\hline
\end{tabular}

Experimental groups inoculated with Dematophora necatrix

$\begin{array}{llllll}\text { Ogliarola } & 48(9) & 1.6-2.1 & 26 / 10 / 2018 & \text { N.P. } & 14 / 01 / 2020(445) \\ \text { I. Leccino } & 30(5) & 0,8-1,1 & 09 / 04 / 2019 & \text { N.P. } & 09 / 04 / 2020(366) \\ \text { II. Leccino } & 36(10) & 1,5-2 & 03 / 10 / 2019 & 5 \text { plants, 5/02/20 (241) } & 03 / 10 / 2020(366) \\ & & & 5 \text { plants, C.W.M. } & \\ \text { I. Favolosa } & 8(10) & 0,4 & 05 / 04 / 2019 & \text { N.P. } \\ \text { II. Favolosa } & 18(20) & 0,4-0,7 & 27 / 01 / 2020 & 10 \text { plants 24/02/2020 (106) } & 9 / 06 / 2020-\text { death }(134) \\ & & & & 10 \text { plants C.W.M. } & 25 / 01 / 2021(364)\end{array}$

Experimental group inoculated with Emmia lacerata (four isolates, five plants per isolate)
III. Favolosa $27(20)$
$29 / 10 / 2020$
20 plants, $24 / 11 / 2020$
$1 / 04 / 2021(154)$

${ }^{1}$ N.P. Not Performed, C.W.M. Control Without Marcottage
${ }^{2}$ The II inoculation trial on Leccino' started before we became aware that margotting could enhance symptom expression, thus it was
applied lately, i.e. three months after removal of the inoculation coverage. On the contrary in the II inoculation trial on Favolosa' marcottage
was applied soon after the removal of the inoculation coverage

Five (Leccino') and 10 ( Favolosa') sterile PDAinoculated plants were used as a control in each inoculation round and for each modality.

The status of plants was monitored until death or for one year in the case of survival. At the end of the trials, the length of the external bark necrosis/canker and internal wood discoloration was recorded. The length of the external healing reactions and of the corresponding wood discolouration behind them was also recorded in the control plants. Fungal re-isolation was performed on streptomycin-supplemented PDA plates.

Marcottage was applied to all plants inoculated with Emmia lacerata. Re-isolations were conducted from the wood behind the inoculation point and from wood collected 3-4 $\mathrm{cm}$ above and below.

To compare the results obtained on plants inoculated in different seasons, or with different methods, the average values of the reactions obtained on the control plants were subtracted from lesion values obtained on the corresponding fungus-inoculated plants.

In vitro test to assess the sensitivity of Dematophora necatrix to (potential) fungicides

Two different assays were set up to assess the effects of seven systemic (potential) fungicides on D. necatrix: i) product-supplemented agar medium assay, and ii) product-supplemented liquid medium assay.
Product-supplemented agar medium assay. PDA medium was supplemented with the products after autoclaving and cooling at approximately $35-40{ }^{\circ} \mathrm{C}$. Fifteen mycelium plugs were taken from actively growing pure colonies, placed in three product-supplemented PDA plates $90 \mathrm{~mm}$ in diameter (five for each plate), and incubated at $25{ }^{\circ} \mathrm{C}$ in the dark for 6 days. As a control, inoculation of non-supplemented PDA plates was always performed according to the same experimental design. If there was no growth, the viability of the fungus was checked by transferring the plugs onto fresh nonsupplemented PDA plates to assess the fungicidal/ fungistatic activity of the product. On the other hand, in cases of growth on the product-supplemented medium, we established the growth rate of $D$. necatrix in the supplemented compared with the non-supplemented medium. For this purpose, five replications were used for each treatment and each PDA plate was inoculated with one fungal plug. Growth measurements were carried out after 10 days, as described above, and the medium daily growth was calculated. Percentage inhibition (PI) of mycelial growth was calculated by Vincent's equation (Vincent, 1947), PI =100 (C-T)/C (where C = rate of growth of the control, measured in $\mathrm{mm} / 24 \mathrm{~h} ; \mathrm{T}=$ rate of growth on product-supplemented plates, measured in $\mathrm{mm} / 24 \mathrm{~h})$.

Product-supplemented liquid medium assay. Five mycelium plugs ( $9 \mathrm{~mm}$ in diameter) were added to $50 \mathrm{ml}$ tubes 
containing $25 \mathrm{ml}$ autoclaved potato dextrose broth (PDB) (Condalab, Torrejón de Ardoz, Madrid, Spain) or water, supplemented with the compounds. Three tubes were used for each PDB or water-based treatment. Positive and negative controls were carried out using tubes containing PDB and water non supplemented with any compound and with fungal plugs or sterile plugs added respectively. The cultures were incubated at $25{ }^{\circ} \mathrm{C}$ in the dark, under $70 \mathrm{rpm}$ shaking for 6 days. The plugs were then pulled out of the tubes, briefly drained of excess liquid by placing them on sterile filter paper discs, transferred onto fresh nonsupplemented PDA plates (five plugs per plate) and incubated at $25{ }^{\circ} \mathrm{C}$ in the dark. The absence of growth attested the biocidal effect of the tested product. Thus, the liquid medium assay was used to confirm the qualitative results obtained with agar medium assay, i.e., keeping viability vs loss of viability.

Dematophora necatrix isolate CREA-DC TPR OL.82, was tested with both assays. Once it was clear that the liquid medium assay had confirmed results of the agar medium assay, we tested an additional $D$. necatrix isolate, CREADC TPR OL.89, with the agar medium assay alone. The products, their active principles and concentrations used are reported in Table 3.
Control with treatment-and-inoculation tests

Treatment-and-inoculation tests were carried out on cv Favolosa' to assess whether the selected products, among those previously tested in vitro, could reliably control the fungal infection in planta. Dentamet, Alphosphite and Thiophanate methyl were used separately in a curative modality, and in a preventive + curative modality (hereafter preventive). Plants were $50-60 \mathrm{~cm}$ in height at the inoculation time of the curative trial, and $70-80 \mathrm{~cm}$ at the inoculation time of the preventive trial.

In the curative trial, plants were treated with the products one month after the inoculation (26 Nov 2019), then 15 days after the first treatment (on 11 Dec 2019), and 30 days after the second one (10 Jan 2020). In the preventive trial, we carried out four treatments with a time interval of 10 days, of which the first two were made 14 and 4 days before the inoculation (22/09 and 2/10/2020). The third and fourth treatments were carried out on $12 / 10$ and 22/10/2020. A fifth treatment was performed twenty days after the fourth one, i.e., on 11/11/2020.

To guarantee a systemic movement of the compounds in the interior of the plants, the products were sprayed on the foliage and also applied through soil drenching. Specifically, $350 \mathrm{ml}$ of the product aqueous suspension was supplied to the soil at the same

Table 3 Products tested in the agarized and liquid medium assays to establish the sensitivity of Dematophora necatrix isolates. The concentration of use of the products was selected from their how to use label relating field applications

\begin{tabular}{|c|c|c|c|}
\hline $\begin{array}{l}\text { (potential) fungicides } \\
\text { (commercial name) }\end{array}$ & Active ingredient & $\begin{array}{l}\text { Product concentrations } \\
\text { used in the in vitro assays }\end{array}$ & Company \\
\hline Dentamet & $\begin{array}{l}\text { copper }(2 \%) \text {, zinc }(4 \%) \\
\text { citric acid }(23.8 \%)\end{array}$ & $\begin{array}{l}5 \mathrm{ml} / \mathrm{lt} \\
(0.5 \%)\end{array}$ & DiAgro s.r.l. \\
\hline Specialfos & $\begin{array}{l}\text { K-phosphite } \\
\mathrm{P}_{2} \mathrm{O}_{5}(30 \%), \mathrm{K}_{2} \mathrm{O}(20 \%)\end{array}$ & $\begin{array}{l}3 \mathrm{ml} / \mathrm{lt} \\
(0.3 \%)\end{array}$ & AL.FE s.r.l. \\
\hline Elios WG Top (Fosetyl-Al) & $\begin{array}{l}\text { Al-ethyl-phosphite }(80 \%) \\
\text { [aluminum tris (O-ethyl phosphonate)] }\end{array}$ & $\begin{array}{l}6.7 \mathrm{mM} \\
(3 \mathrm{~g} / \mathrm{lt})\end{array}$ & Sipcam Italia S.p.A. \\
\hline pHUSION & Silicon phosphite formulation & $5 \mathrm{ml} / \mathrm{lt}$ & Orion Future Technology \\
\hline Mystic 430 SC & $\begin{array}{l}\text { Tebuconazole } \\
(40.18 \%, 430 \mathrm{~g} / \mathrm{lt})\end{array}$ & $0.45 \mathrm{ml} / \mathrm{lt}$ & Nufarm Italia s.r.l. \\
\hline Tilt@ 25 EC & $\begin{array}{l}\text { Propiconazole } \\
(250 \mathrm{~g} / \mathrm{lt})\end{array}$ & $0.25 \mathrm{ml} / \mathrm{lt}$ & Syngenta Italia S.p.A. \\
\hline Enovit Metil® FL & $\begin{array}{l}\text { Thiophanate methyl } \\
(41.7 \%, 500 \mathrm{~g} / \mathrm{lt})\end{array}$ & $1.1 \mathrm{ml} / \mathrm{lt}$ & Sipcam Italia S.p.A. \\
\hline
\end{tabular}


concentration used in the in vitro assays (Table 3). At the same time, the same product suspension, containing $0.01 \%$ (v/v) Silwet L-77 as a surfactant, was finely sprayed on the canopy with a dispenser-pump. Inoculations and marcotting technique were as described above. Water-treated and D. necatrix-inoculated controls were set up in parallel. To monitor phytotoxicity, six plants were subjected to the treatment calendars with each product without being inoculated. Three of these were wounded and inoculated with sterile PDA. Additional details are given in Table 4. Symptom monitoring, recording and fungal re-isolations were as described in the chapter entitled "Inoculation trials to assess fungal pathogenicity".

Statistical analyses

A one-way fully randomized analysis of variance (ANOVA or Welch test) and the Tukey test as post-hoc analysis, were carried out to compare the fungal growth at different temperatures, the growth of the different fungal isolates, the different growth conditions (dark and light) and growth on product-supplemented media. For the productsupplemented media we used the percentage inhibition values after arcsine transformation. PAST version 4.03 was used for the analysis (Hammer et al., 2001).

Pathogenicity data were analysed by ANOVA with pairwise Tukey's test as post hoc, and MANOVA (Multivariate Analysis of Variance) with pairwise Hotelling's test as post hoc. In the analyses, the inoculation season and the inoculation method (with and without marcottage) were the treatments. Discolouration length of bark and wood separately were included as quantitative data.

Survival analyses: Kaplan-Meier estimate, log-rank test

We recorded the death dates of the inoculated trees treated with the products in preventive modality and calculated the survival time expressed in days (from the inoculation to death). Treatment group data were then used for the survival analyses according to the Kaplan-Meier estimate (Kaplan \& Meier, 1958; Bewick et al., 2004; Goel et al., 2010; Rich et al., 2010). We thus inferred stepped survival curves for each treatment group estimating and graphing the cumulative survival probabilities (Y-axis) as a function of time. In the curves the terminal end of each horizontal line is the occurrence of death for one or more plants, which decreases the cumulative survival probability for the still surviving plants (vertical line). In this study, censored trees were all those still surviving at the end of the observation period, namely censoring occurred exclusively at the end of the study for reasons strictly linked to the capacity of plants to overcome the disease. No plants were lost to follow up for $D$. necatrix-linked-death or survival.

We compared the survival pattern of each group data by the log-rank test. The log rank test was calculated as follows: $\chi^{2}(\log$ rank $)=(\mathrm{O} 1-E 1) \frac{2}{E 1}+(\mathrm{O} 2-E 2) \frac{2}{\mathrm{E} 2}$ where the $\mathrm{O}_{1}$ and $\mathrm{O}_{2}$ are the total numbers of observed events in groups 1 and 2, respectively, and $\mathrm{E}_{1}$ and $\mathrm{E}_{2}$ the total numbers of expected events (Mantel, 1966; Peto \& Peto, 1972; Bewick et al., 2004; Goel et al., 2010).

Analyses were conducted in R, v. 4.1 .0 (2021-05-18) - Camp Pontanezen (R core Team, 2021). We used the package for survival analysis by Therneau (2021), based on Therneau \& Grambsch (2000).

\section{Results}

Symptom description

At the time of our survey and within a time frame of one year, more than 80 plants (including original plants and replacements) had died. All the trees had been planted by burying $20-30 \mathrm{~cm}$ of the basal portion of the stem. Wilting and death of the trees was the final outcome of the disease. Observations of trees in earlier and later phases of the disease clearly suggested that wilting began with a downward leaf rolling, then leaves turned from dark green to red-bronze and finally brown. Dried leaves persisted on the twigs. This course clearly suggested a process of water leaking from leaf blades not compensated for by an adequate absorption at the root level or transport in the stem. White, cottony mycelial strands emanating a strong mushroom smell were wrapped around the basal portion of the stem that had been buried during planting. Correspondingly, the bark had rotted and the xylem was heavily affected by a brown-reddish discolouration (Fig. 1). Wood discolouration and bark rotting also tended to extend up to the air-exposed portion of the stem and down to the main roots.

Isolation and detection results, molecular/phylogenetic identification of the fungi

10 symptomatic and four asymptomatic plants were sampled and used for fungal isolation. Several fungi 
Table 4 Treatment-and-inoculation tests carried out on cv Favolosa' to assess the power of the chemical products for curative and preventive control

\begin{tabular}{|c|c|c|c|c|c|c|}
\hline Trial & Treatment & $\begin{array}{l}\text { Age in months } \\
\text { (replicates) }\end{array}$ & $\begin{array}{l}\text { Stem diameter at } \\
\text { the inoculation point } \\
(\mathrm{cm})\end{array}$ & $\begin{array}{l}\text { Date of } \\
\text { inoculation }\end{array}$ & $\begin{array}{l}\text { Date of } \\
\text { marcottage }^{1}\end{array}$ & Survival days \\
\hline \multirow[t]{4}{*}{ Curative } & water & $15(9)$ & $0.4-0.6$ & $24 / 10 / 2019$ & $22 / 01 / 2020$ & $179-200$ \\
\hline & Dentamet & $15(7)$ & $0.4-0.6$ & $24 / 10 / 2019$ & $22 / 01 / 2020$ & $178-199$ \\
\hline & Tiophanate methyl & $15(7)$ & $0.4-0.6$ & $24 / 10 / 2019$ & $22 / 01 / 2020$ & $178-213$ \\
\hline & Al-phosphite & $15(7)$ & $0.4-0.7$ & $24 / 10 / 2019$ & $22 / 01 / 2020$ & $178-213$ \\
\hline \multirow[t]{4}{*}{ Preventive } & water & $26(10)$ & $0.6-0.9$ & $6 / 10 / 2020$ & $30 / 10 / 2020$ & $151-218$ \\
\hline & Dentamet & $26(10)$ & $0.6-0.9$ & $6 / 10 / 2020$ & $30 / 10 / 2020$ & $151-225$ \\
\hline & Tiophanate methyl & $26(10)$ & $0.6-0.9$ & $6 / 10 / 2020$ & $30 / 10 / 2020$ & $100 \%$ survival \\
\hline & Al-phosphite & $26(10)$ & $0.6-0.9$ & $6 / 10 / 2020$ & $30 / 10 / 2020$ & $\begin{array}{l}213-287, \\
1 \text { survivor }\end{array}$ \\
\hline
\end{tabular}

\footnotetext{
${ }^{1}$ The curative trial started before we became aware that margotting could enhance symptom expression, thus it was applied lately, i.e. two months after removal of the inoculation coverage. On the contrary in the preventive trial marcottage was applied soon after the removal of the inoculation coverage
}

were obtained from all the samples. A fungal colony was repeatedly obtained from nine diseased trees (out of ten) thus suspected as having a possible role in the observed disease. On the other hand, another fungal morphotype was obtained from almost all the trees sampled, both diseased and healthy-looking (13 out of 14). To verify if the latter fungus was a common endophyte in olive trees, we carried out isolations from the stem of 15 healthy-looking olive plants - five mature trees plus 10 potted Favolosa' plants - growing in the garden and the nursery of CREA-DC laboratories in Rome. This fungus was not detected from these sources.

Real-time PCR ruled out the presence of Xfp and $V$. dahliae in all the samples collected in the field.

We generated 43 ITS sequences from as many fungi isolated from the collected samples. In the Blastn suite, these ITS sequences aligned with $100 \%$ or a high nucleotide percentage identity with subjects representing several fungal taxa within Ascomycota and Basidiomycota (Online Resource 5). Specifically, the ITS sequences of the fungal species recurring in the symptomatic trees, matched with a 99.7-99.8\% nucleotide identity with Rosellinia/Dematophora necatrix (Ascomycota, Pezizomycotina, Sordariomycetes, Xylariales, Xylariaceae) and were identical to each other. Regarding three representative isolates, we generated nine sequences representing nLSU, TUB2 and RPB2. Launching these sequences in the Blastn suite gave the same matches as the ITS region with a high/maximum percentage nucleotide identity (Online Resource 5).
The multi-locus phylogenetic tree of Xylariaceae rooted as expected, and fully matched the topology of the phylogenetic tree reported by Wittstein et al. (2020): sequences of isolates of $D$. necatrix from olive, generated in this study, grouped with the maximum bootstrap value with reference $D$. necatrix (Fig. 2).

ITS sequences of the fungus associated with both diseased and healthy-looking trees -Emmia-like matched with a $99.8-100 \%$ nucleotide identity, with subjects classified as Emmia (Ceriporia) lacerata (Maek., Suhara \& Kondo) Wu, Chen \& Dai. (Basidiomycota, Agaricomycotina, Agaricomycetes, Polyporales, Irpicaceae) (voucher specimen FP-55521T). All ITS sequences of Emmia-like isolates from olive had 99.7-100\% nucleotide identity. A Blast search with nLSU obtained from these isolates gave $100 \%$ nucleotide identity with Emmia (Ceriporia) lacerata(Online Resources 5).

The multi-locus phylogenetic tree of the Phlebioid clade rooted as expected and fully matched the topology of the phylogenetic tree reported by Chen et al. (2020). Three well-supported clades were inferred representing the three families of the Phlebioid clade: Irpicaceae, Phanerochaetaceae and Meruliaceae. A sub-grouping within Irpicaceae i.e., clades 1, 2 and 3 sensu Chen et al. (2020) was also detected. Sequences of the Emmia-like isolates from olive, clustered within clade 3 of Irpicaceae. Specifically, they grouped with the maximum or a very high bootstrap value with sequences of isolates named as E. lacerata, Ceriporia lacerata 
Fig. 1 Symptoms affecting the olive trees in the grove: $\mathbf{a}$ and $\mathbf{b}$ canopy wilting and persistence of dried leaves on the branches; $\mathbf{c}$ and $\mathbf{d}$ white mycelial strands wrapping the basal portion of the stem that had been buried; e wood discolouration and rotting
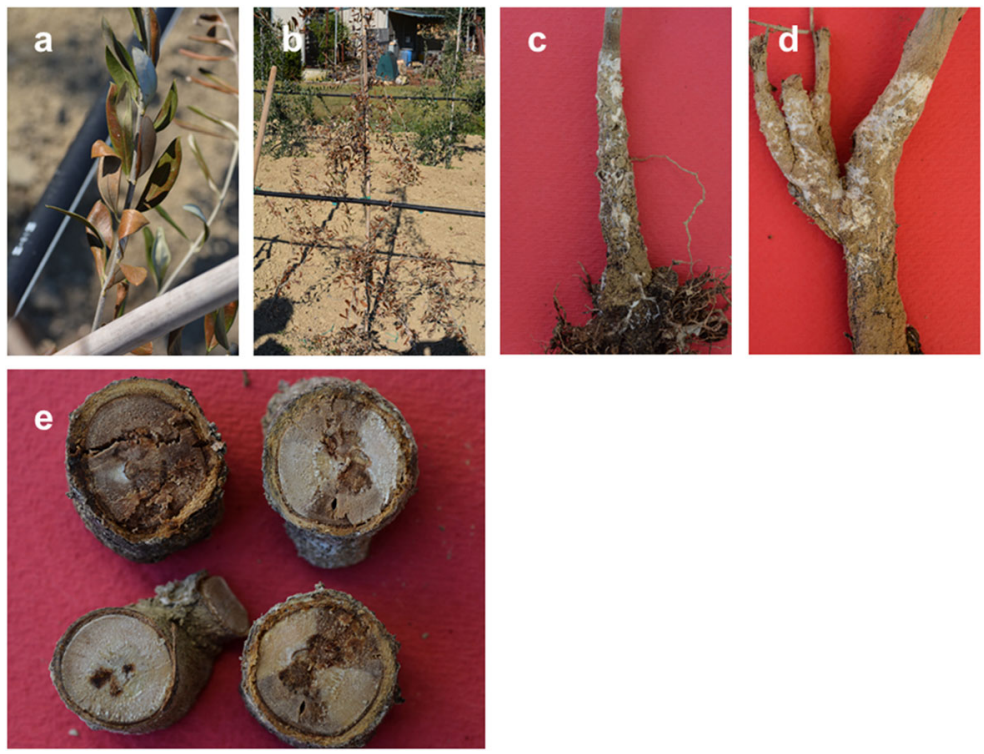

(Maek., Suhara and Kondo), and E. latemarginata (Durieu et Mont.) Zmitr., Spirin. et Malysheva. For readability, Fig. 3 presents a phylogenetic tree with representative reference species, while Online Resource 6 contains a more complete version of the tree.

As $C$. lacerata and $E$. latemarginata are homotypic synonyms of $E$. lacerata and use of $E$. lacerata has been established (Wu et al. 2017), from this point forward we use this name to refer to this taxon. Other basidiomycetous taxa detected were: Phlebia acerina, Trametes versicolor and Porostereum spadiceum.

Structural and growth features of Dematophora necatrix and Emmia lacerata

As PDA-grown axenic cultures, the colonies that had been sequence-identified as $D$. necatrix developed a white cottony mycelium which became fluffy after one week, and then darker from two weeks onwards (Fig. 4). In this phase, mycelium also started producing black microsclerotia which were visible on the back of the colony-plate. Hyphae were hyaline and dark-brown pigmented. After two days of PDA culturing, hyphae began to develop pear-shaped swellings next to the septum, which is a diagnostic feature of Dematophoral Rosellinia necatrix (Pérez-Jiménez, 2006; Schena et al., 2008; Pliego et al., 2012) (Fig. 5). The measurements of the pear-shaped swellings in three PDA-grown isolates gave average values of $8.2 \mu \mathrm{m}$ (isolate CREA-DC TPR
OL.82, $\mathrm{SD}=2.1, \mathrm{n}=100$ ), $9.1 \mu \mathrm{m}$ (isolate CREA-DC TPR OL.86, $\mathrm{SD}=1.5, \mathrm{n}=85$ ), and $7.7 \mu \mathrm{m}$ in diameter (isolate CREA-DC TPR OL.89, $\mathrm{SD}=1.1, \mathrm{n}=102$ ). The growth rate of $D$. necatrix isolates on PDA was progressively higher from 15 to $25^{\circ} \mathrm{C}$. The isolates grew very little at 10 and $30^{\circ} \mathrm{C}$, and did not grow at all at 35$40{ }^{\circ} \mathrm{C}$, while keeping viability up to $35^{\circ} \mathrm{C}$ and losing it at $40{ }^{\circ} \mathrm{C}$. All differences were detected with $\mathrm{p}<0.01$ (Fig. 6).

Several black sclerotia in spherical nodules of no more than $1 \mathrm{~mm}$ in diameter, developed on the canker lesions of the dead trees which had been inoculated with D. necatrix using the marcottage method. Sclerotia emerged from the rotted bark alongside a black sclerotial crust that also erupted from the bark (Fig. 5). The inside of the sclerotia had a mycelial texture. The teleomorph state typical of $D$. necatrix, i.e. the stromata, was not found even after incubating the rotted stems in a moist chamber for one month both in the dark or daylight. Although we monitored rotted stems in the moist chamber and fungal cultures on PDA, PDA (or agarwater) + autoclaved wheat kernels, for 1-2 months, synnemata conidiogenous cells bearing conidia were not observed.

With regard to the fungal isolates that were molecularly identified as E. lacerata, all the colonies in pure culture emitted a mushroom smell. They were white and remained so even after two months. The mycelial mat was fairly flat, thick and consistent, soft-waxy, with a moderate, sparse fluffiness. Mycelium tended to climb 


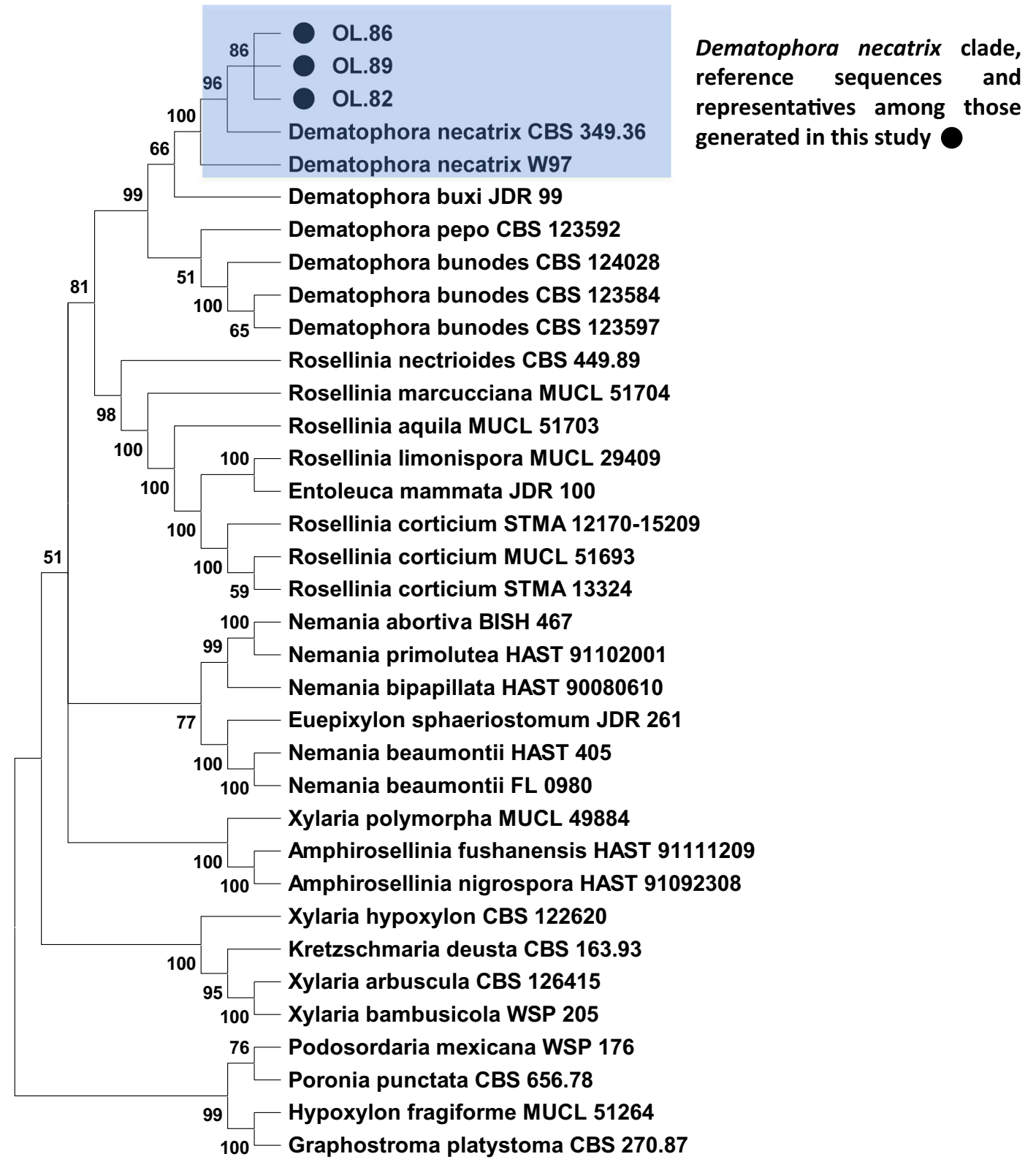

Fig. 2 Phylogeny of selected Xylariaceae, Hypoxylaceae and Graphostromataceae including Dematophora/Rosellinia species, based on ITS+28S + TUB2 + RPB2 data set (according to Wittstein et al., 2020) and inferred using the ML method and General Time Reversible model (Nei and Kumar, 2000), with 1000 bootstrap. The tree with the highest log likelihood $(-40,785.06)$ is shown. The percentage of trees in which the associated taxa clustered together is shown next to the branches. Branches with values lower than 50 were collapsed (condensed tree). Initial tree(s) for the heuristic search were obtained automatically by applying Neighbor-Join and BioNJ algorithms to a

the internal border of the plate, frequently forming palisade-like mycelial structures. Similarly with Suhara matrix of pairwise distances estimated using the Maximum Composite Likelihood (MCL) approach, and then selecting the topology with superior log likelihood value. This analysis involved 35 nucleotide sequences. There were 4609 positions in the final dataset. Evolutionary analyses were conducted in MEGA X (Kumar et al., 2018). Sequences newly generated in this study from fungi isolated from olive are named with alphanumeric codes and labelled with black circles (for brevity only a part of the voucher-specimen code is reported here; for the whole code see Table 1)

(2003), the E. lacerata isolate CREA-DC TPR OL.131 developed on PDA, in pure culture, an irpicaceous white 


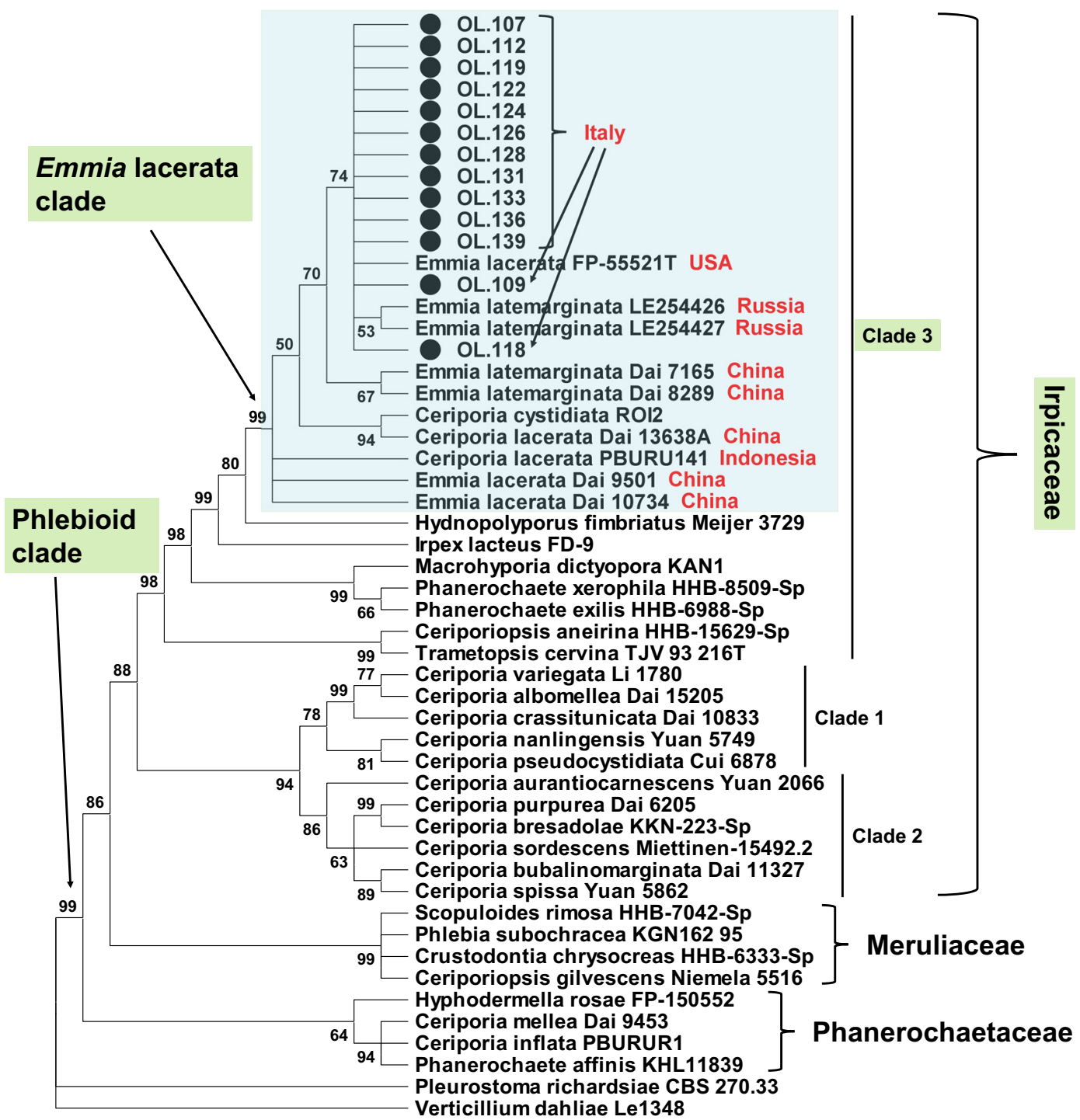

Fig. 3 Phylogeny of the Phlebioid clade based on the ITS+28S data set and inferred using the ML method and General Time Reversible model (Nei and Kumar, 2000), with 1000 bootstraps. The tree with the highest log likelihood $(-17,018.06)$ is shown. The percentage of trees, higher than 50 , in which the associated taxa clustered together, is shown next to the branches. Branches with values lower than 50 were collapsed (condensed tree). Initial tree(s) for the heuristic search were obtained automatically by applying Neighbor-Join and BioNJ algorithms to a matrix of pairwise distances estimated using the Maximum Composite
Likelihood (MCL) approach, and then selecting the topology with superior log likelihood value. This analysis involved 51 nucleotide sequences. There were 2458 positions in the final dataset. Evolutionary analyses were conducted in MEGA X (Kumar et al., 2018). Sequences newly generated in this study from fungi isolated from olive are named with alphanumeric codes and labelled with black circles (for brevity only a part of the voucher-specimen code is reported here; for the whole code see Table 1). Clades 1, 2, 3 in the Irpicaceae were sensu Chen et al. (2020)

isolates, CREA-DC TPR OL.109 and 126, developed very small rudimentary hymenophore-like structures on the internal border of the plate (Fig. 7), frequently with droplets. Nevertheless, they were able to produce basidiospores which measured: 4.7-7.6 $\mu \mathrm{m}(\mathrm{M}=5.8, \mathrm{SD}=$ $0.5) \times 2.9-4.5 \mu \mathrm{m}(\mathrm{M}=3.8, \mathrm{SD}=0.3)(\mathrm{n}=72)$ and 
Front
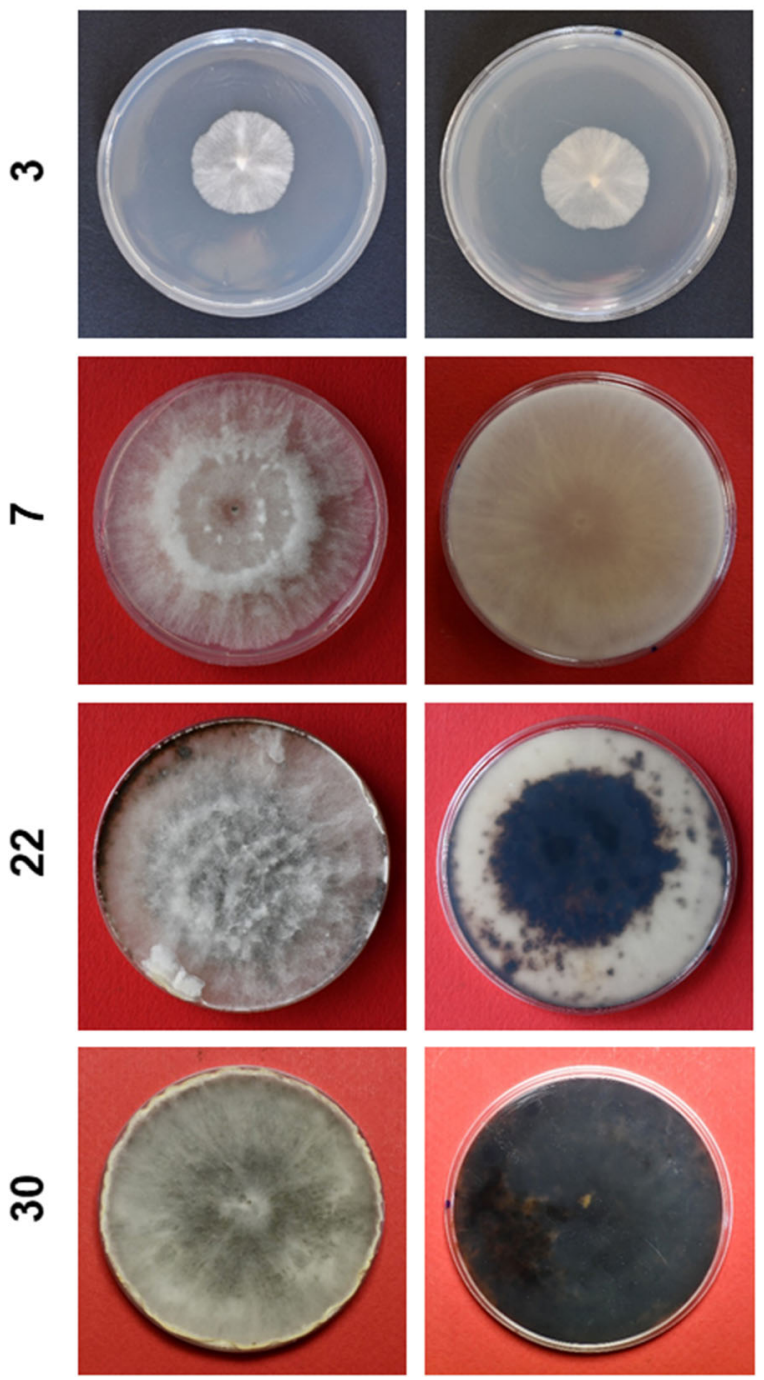

Fig. 4 Morphological evolution over time of Dematophora necatrix isolated from olive trees and grown as an axenic culture on PDA. Lateral numbers indicate the age of the cultures in days

$4.7-6.8 \mu \mathrm{m}(\mathrm{M}=5.6, \mathrm{SD}=0.4) \times 3.0-5.3 \mu \mathrm{m}(\mathrm{M}=$ $3.8, \mathrm{SD}=0.4)(\mathrm{n}=63)($ Fig. 7$)$. When treated with Melzer reagent (Melzer, 1924), basidiospores of the isolates were inamyloid. Mycelium was cyanophilous. These morphological features were consistent with those of E. lacerata thus supporting the results of our molecular/phylogenetic analyses.

\section{Pathogenicity tests}

In the pathogenicity trials, D. necatrix caused mild or severe stem cankers progressing upward and downward from the inoculation point. The bark was affected by necrosis and was dried and brown-orange discoloured in the plants without marcottage, but rotting and brownish/ blackish in the plants with marcottage. The xylem was heavily affected by a dark or greyish discolouration. A complete loss of viability occurred via: i) a rapid canopy wilting characterized by a downward leaf rolling, a rapid colour change from green to brown with dead leaves persisting on the twigs, and ii) a slow decline with leaf yellowing and fall. Disease symptoms were reproduced on all cultivars tested.

Inoculation in the winter and autumn and the application of marcottage at the inoculation point led to more severe symptom expression compared with the spring inoculation and no use of marcottage. In fact, in Favolosa' ANOVA and MANOVA analyses revealed high levels of significance regarding discoloration streaks in the bark and wood (Figs. 8 and 9, Online Resources 7).

The biological significance of the effect of marcottage was further confirmed by the fact that Favolosa' marcotted plants died almost at the same time, and were completely wilted after 134 days, except one that wilted after 97 days. White, cottony mycelial strands of $D$. necatrix around the stem, emerged from the substrate of marcottage. The borders between the advancing necrosis and the healthy tissue (reaction zone) were devoid of any callus overgrowth. The results of the inoculation of marcotted plants (Figs. 8 and 9) were fully reproduced in two subsequent trials performed by inoculating marcotted plants and aimed at evaluating the efficacy of the (potential) fungicide. On the other hand, all non-marcotted plants still had a normal vegetative condition one year after the inoculation, although they were affected by non-healing and slightly healing cankers (Figs. 8 and 9).

In Leccino', the effects of inoculation season and of marcottage on discoloration streaks were also clear, though with a weaker statistical support (Online Resources 7). However, the higher severity of the autumn inoculation was further supported by the fact that all the plants inoculated in autumn gradually lost between 40 and $95 \%$ of their leaves, whereas plants inoculated in the spring kept a normal vegetation similar to that of the non-inoculated control. In Leccino', the biological significance of marcottage was confirmed by the fact that two marcotted plants (out of the five inoculated in autumn) were dead at the moment of the final recording, whereas all five non-marcotted plants of the 
Fig. 5 Morphological features of Dematophora necatrix from olive. a Mycelial strands developed on inoculated plants. $\mathbf{b}$ Black sclerotia and sclerotial crusts emerging from the rotted bark of the stem of inoculated plants. c Hypha with typical pearshaped swellings immediately adjacent to the septum
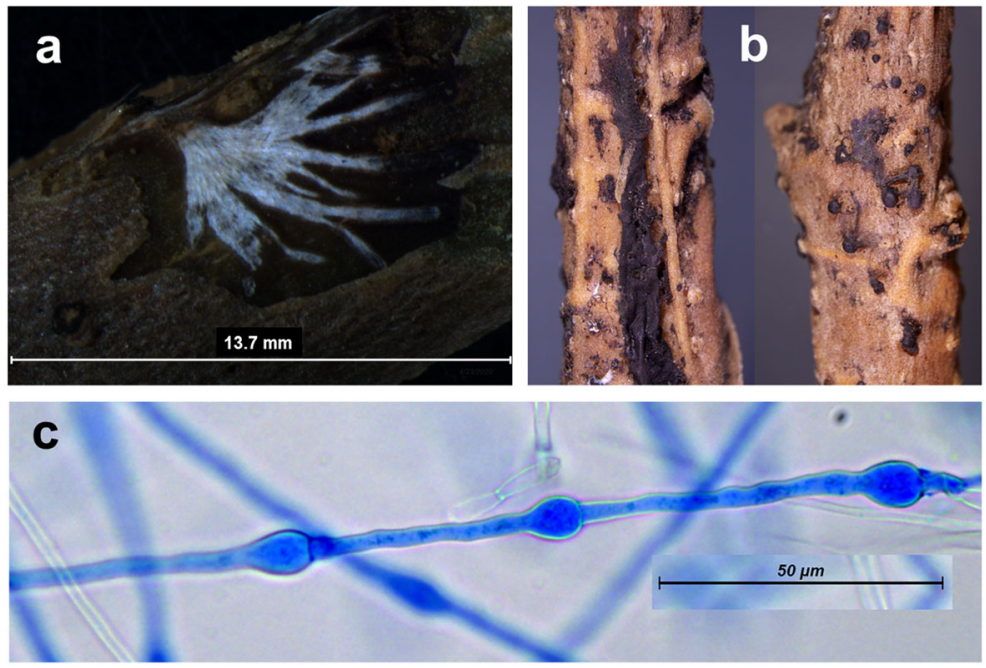

parallel experimental group were still surviving, though declining. In addition, bark cankers were more severe in marcotted plants, compared with non-marcotted plants (Figs. 10 and 11).

Dematophora necatrix also caused severe symptoms on Ogliarola' (which was only inoculated in the autumn), such as non-healing and slightly healing cankers. Mean bark necrosis and wood discolouration reached $8.3 \pm 0.71(\mathrm{SE})$ and $8.6 \pm 0.74(\mathrm{SE}) \mathrm{cm}$, respectively. Moreover, three out of ten plants died after 158207 days.

Trees inoculated with E. lacerata isolates were recorded after 5 months and no decline symptoms or pathological alterations in colour and consistency of wood were present. Re-isolations from wood at the inoculation point were successful for three isolates (out of four tested) in a total of eight trees (out of 20 tested) (two trees with CREA-DC TPR OL.109, two trees with OL.126, three trees with OL.133, none with OL.139). Isolations were always negative when the wood collected 3-4 cm above and below the inoculation point was tested.

Controls inoculated with sterile PDA, with or without marcottage, always showed a normal vegetative condition, complete healing of the inoculation wound, and a very slight and reduced wood discoloration behind it.

In vitro sensitivity of Dematophora necatrix to (potential) fungicides and in planta control trials

The sensitivity of $D$. necatrix to (potential) fungicides was tested in vitro with the agarized and liquid medium assays. The liquid medium assays based on PDB and water confirmed results obtained with the agar medium assay, by assessing the fungicidal effect vs survival. The results obtained with CREA-DC TPR OL.89 on the agarized medium assay matched those obtained with CREA-DC TPR OL.82. Propiconazole and Thiophanate methyl caused death of the fungal isolates, Dentamet and Al-phosphite caused a complete growth inhibition, however without compromising fungal viability. Growth inhibition was slightly reduced with Siphosphite, Tebuconazole and K-phosphite, which caused a 92/100, 91/100, 79/85\% reduction in growth, respectively. The results are reported in Table 5 and Online Resource 8.

We thus selected Thiophanate methyl, Al-phosphite and Dentamet for use in treatment-and-inoculation trials to test the effectiveness in controlling the disease in planta, with a curative and a preventive treatment modality. In control plants inoculated with PDA and treated with water and the products, in both curative and preventive trials, there were no symptoms of phytotoxicity, or cankering/rotting at their inoculation wounds. In the preventive trials, given the long duration (11 months, October 2020 to August 2021), the inoculation wounds had completely healed.

In the curative trial, none of the plants in all the experimental plots inoculated with $D$. necatrix, produced new leaves in spring, and died over the course of 178-213 days with sudden wilting and severe stem rot. Plants treated with Thiophanate methyl and Alphosphite had a somewhat longer survival time (178213 days), compared with plants treated with Dentamet and the water-treated control (178-199/200 days). 

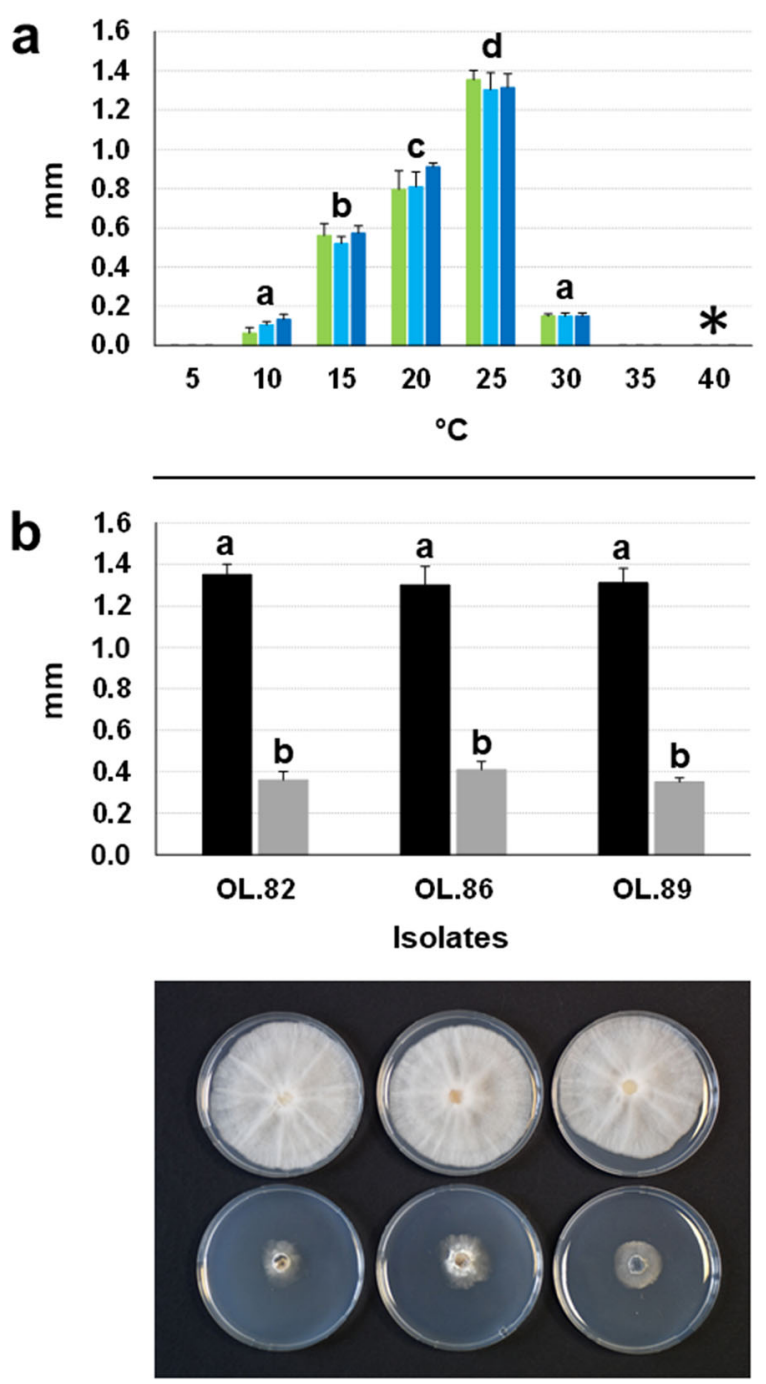

Fig. 6 Daily growth of three isolates of Dematophora necatrix in axenic culture on PDA (CREA-DC TPR OL. 82 in green, CREADC TPR OL.86 in pale blue, CREA-DC TPR OL.89 in blue). a Growth trend in the range $5-40{ }^{\circ} \mathrm{C}$; the asterisk indicates loss of viability. b Growth at $25{ }^{\circ} \mathrm{C}$ in continuous dark (black bars) and light (grey bars) conditions. The photo depicts representative colonies, those at the top grown in the dark, those below grown in the light (the order of the isolates is the one shown in the graph). Statistical analysis was conducted for each isolate in relation to the different temperatures and the dark/light growth conditions. Different letters indicate significant differences from each other $(\mathrm{p}<$ 0.01 ). Statistical comparison among the isolates at each temperature did not evidence significant differences

In the preventive trial, all plants inoculated with D. necatrix and treated with water, Dentamet and Alphosphite showed a disease course and symptoms similar to those of the curative trial and died over 151-218, 151-225 and 213-287 days, respectively. Just one plant treated with Al-phosphite survived in good growth conditions until the end of August 2021, when it was decided to end the entire trial and all survivors were subjected to a destructive recording. All plants treated with Thiophanate methyl survived the 11 months of the study. Kaplan-Meier curves based on survival time of the differently treated plants clearly showed that the survival of water and Dentamet-treated plants was not significantly different. On the other hand, deaths that occurred in plants treated with Al-phosphite were significantly delayed. In line with the results described above, the Thiophanate methyl curve was significantly different from all the others, with the highest statistical significance, maintaining the maximum cumulative survival probability, namely the survival time of all the participating subjects was indeterminate. See Fig. 12 for Kaplan-Meier curves and p-values. In addition to the statistical significance (which was exclusively linked to survival time), it is also meaningful that plants treated with the fungicide Thiophanate methyl showed a normal sprouting in spring and the same vegetative growth as non-inoculated controls; moreover, cankers were not present at the inoculation point after removal of marcottage and the inoculation wounds appeared to be strongly healed similarly to non-inoculated controls. Importantly, D. necatrix was never reisolated from wood and bark around the inoculation point of each plant (Online resource 9).

\section{Discussion}

Dematophora/Rosellinia necatrix can severely damage a wide range of woody crops, including Malus spp., Pyrus spp., Prunus spp., Coffea spp., avocado, mango and grapevine. It is present in five continents in temperate, tropical and subtropical zones (Pérez-Jiménez, 2006; Schena et al., 2008; Pliego et al., 2012; Pasini et al., 2016). Dematophora necatrix has been isolated from roots of olive trees in France (Guillaumin et al., 1982), Portugal (Roca et al., 2016), and Spain (Figueres \& Grouard, 2001), and it also infects olive trees in Italy (Faretra \& Frisullo, 2002; Schena et al., 2008; Carlucci et al., 2013b).

White root rot' or Dematophora root rot' is the name of the disease irrespective of the host plant. We thus apply this name to the phytopathological case of this study although the stem rotting feature was preponderant in the observed symptomatology. Wilting 


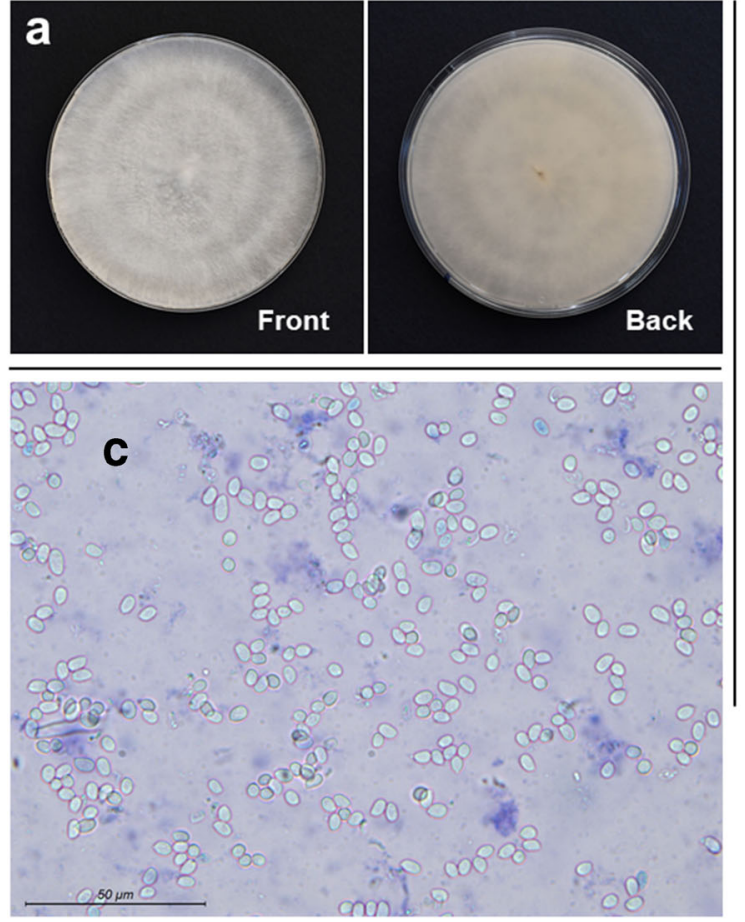

Fig. 7 Morphological features of Emmia lacerata isolates from olive trees. a8-days-old axenic culture on PDA. b Older colonies with rudimentary reproductive hymenium-like structures

symptom and the fact that the affected plants were young olive trees might be reminiscent of syndromes characterized by the collapse of young olive trees, the drying syndrome' ( seca' in Spanish) which was reported in Spain (Sánchez Hernández et al., 1998) and another similar decline phenomenon traceable to drying syndrome', reported in Italy (Lo Giudice et al. 2010). However, differently from the phytopathological case of this study, drying syndromes' were characterized by a multiplicity of pathogenic agents, fungi and oomycetes, acting synergistically and taking advantage of anomalous/extreme environmental conditions. However several points clearly state that the phytopathological case of this study is not dry syndrome-like and is instead an ascertained manifestation of Dematophora root rot': i) in the fields, white mycelial strands wrapped the basal portion of the stem of all diseased plants; ii) D. necatrix was strictly associated with the disease, iii) Koch postulate - performed by mimicking the anomaly in plant management (burying the basal portion of the stem) was fulfilled; iv) other potentially pathogenic microrganisms were absent.

We found pear-shaped swellings at the hyphal septa of all the fungal isolates of the morphotype
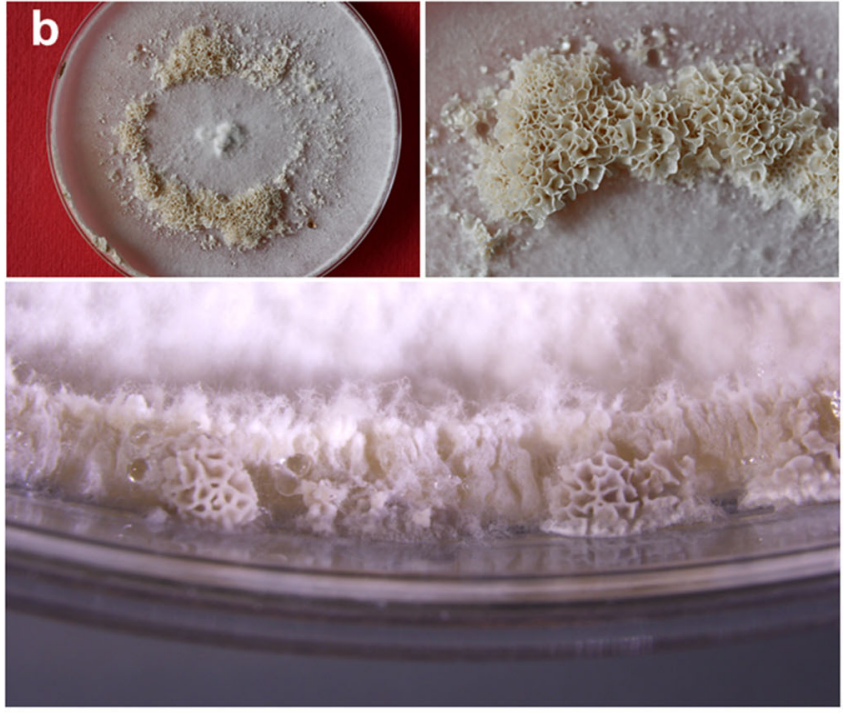

resembling the basidiocarp, active in basidiospore production. c Basidiospores produced by the structures shown in (b)

strictly associated with the diseased trees. This morphological feature is diagnostic for the teleomorph and the anamorph of Rosellinia and Dematophora necatrix, respectively. Schena et al. (2008) summarized the taxonomical background and the early assessments of these sexual and asexual morphs since the first description of the genus Rosellinia in 1844 by De Notaris. Petrini (2013) described Rosellinia necatrix (and other species) as being equipped with Dematophora-like conidiophores, unlike other Rosellinia species which are characterized by a geniculisporium and/or nodulisporium conidiophore type. Clades inferred through a multi-locus phylogenetic analysis by Wittstein et al. (2020) strongly correlated with grouping according to conidiophore types. For this reason, and also considering the "One Fungus - One Species" concept, these authors established the resurrection of Dematophora for the taxa D. necatrix, D. buxi, $D$. pepo and D. bunodes (ex Rosellinia spp.), while keeping other species within the genus Rosellinia sensu strictu.

This reassessment was adopted by the NCBI, which attributed D. necatrix to our sequences with $99-100 \%$ 

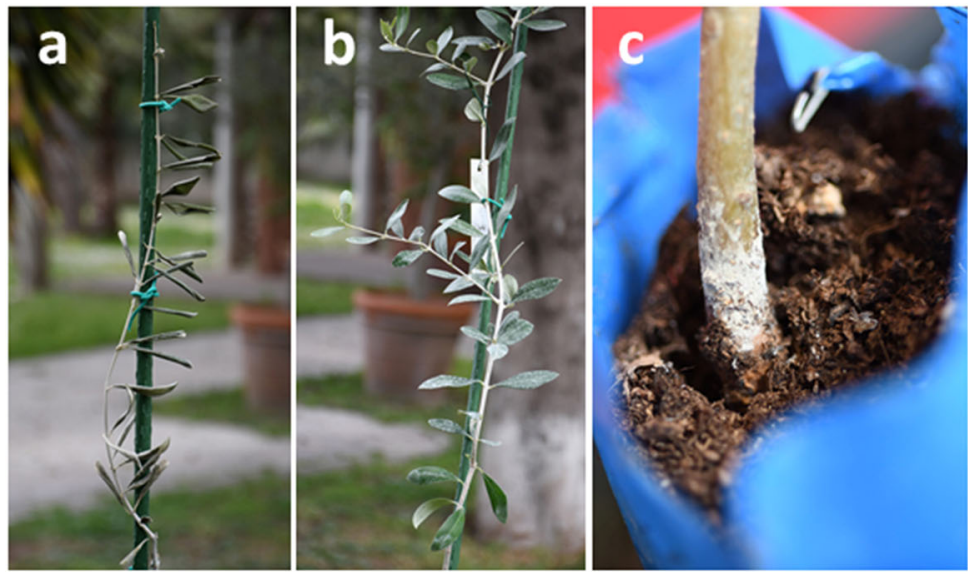
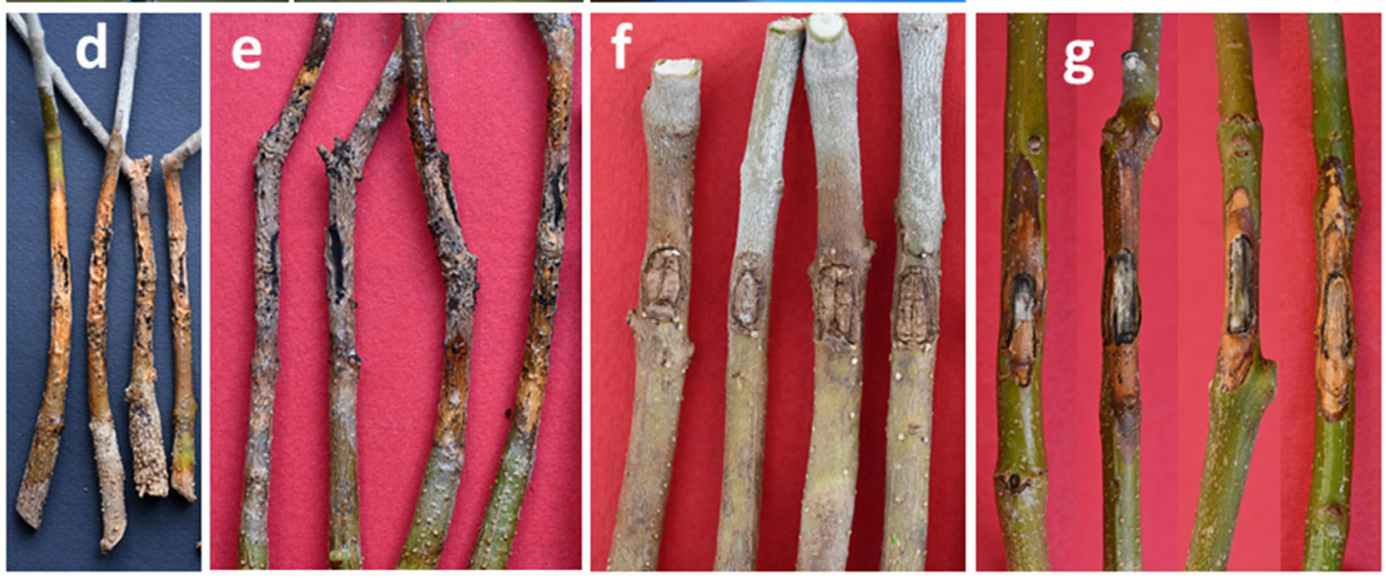

Fig. 8 Symptom expression on representative Favolosa' plants following inoculation in dormant seasons with Dematophora necatrix assisted with marcottage $-\mathbf{a}$ to $\mathbf{f}$, and without marcottage - (g).a Wilting; b sterile PDA-inoculated control; c white mycelial strands wrapping the stem portion that had been inoculated and

percentage identity with Rosellinia/Dematophora necatrix subject sequences (Table 1, Online Resource 5). Although we found no sexual and asexual morphs in our isolates, pear-shaped swellings (Fig. 5) and grouping in the phylogeny with $D$. necatrix with a maximum bootstrap value (Fig. 2) is robust evidence of this identification.

Differences in disease severity were clearly evidenced among plants inoculated in different seasons and with/without marcottage (Figs. 8, 9, 10 and 11). Evidence came from the statistical significance of the discolouration streaks and annotations of the plant health status - normal healthy-like vegetation vs defoliation/decline vs complete loss of viability. The fact that seasons associated with dormancy of plants autumn and winter - and marcottage greatly favoured disease development merits some comments. Using buried with marcottage; $\mathbf{d}$ and e rotting of the stem of the inoculated plants, revealed after removal of marcottage; $\mathbf{f}$ complete healing of sterile PDA-inoculated wounds of control plants; $\mathbf{g}$ canker lesions developing from the inoculation points not covered with marcottage

in vitro tests, we found that the best temperatures for fungal growth are between 15 and $25^{\circ} \mathrm{C}$, the latter being the optimum, and that light strongly inhibits fungal growth. This is in line with contribution to disease by dormancy seasons, frequently characterized by not excessively cold or mild temperatures in Italy, and by dark conditions connected with marcottage. The fact that darkness promotes fungal activity confirms previous reports (Anselmi \& Giorcelli, 1990). However, an additional contribute to virulence by marcottage through the maintenance of a favorable moisture content cannot be excluded. In any case, burying $20-30 \mathrm{~cm}$ of the basal portion of the stem, at the moment of planting, likely favoured plant susceptibility given that most rotting occurred at the stem rather than at the roots. It is also relevant that spring inoculation caused poor symptom expression at the stem level and without jeopardizing 


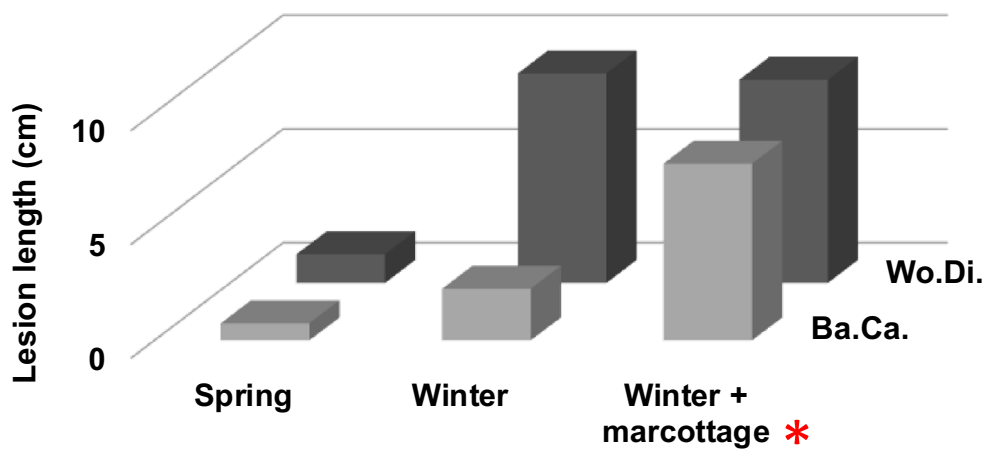

\begin{tabular}{|lr|}
\hline Spring vs winter & $2,86 \mathrm{E}-07$ \\
Winter vs (winter + marcottage) & $5,56 \mathrm{E}-11$ \\
\hline
\end{tabular}

Fig. 9 Length of tissue necrosis - bark canker (Ba.Ca.) and wood discolouration (Wo.Di.) - caused by Dematophora necatrix on Favolosa' plants inoculated in different seasons. In the winter inoculation, the marcottage treatment was also included. The red asterisk indicates that the treatment led to a loss of viability of all

plant viability or even causing some leaf drop, over a one-year time span. The level of virulence of $D$. necatrix on olive trees can thus be strongly modulated by particular conditions, especially those occurring during the infection event, so that the trees range from tolerating the fungus without any severe loss to succumbing. Specifically, the season when the tree is infected is crucial for disease development: i) spring inoculation hindered disease development which did not even accelerate in the following autumn/winter; ii) on the other hand inoculation in dormancy seasons favoured the disease which did not even slow down in the following spring.

Control of Dematophora root rot' is difficult since the fungus can survive for years in the soil as a saprotroph on dead plant residues, can move underground in the form of mycelial fans, and can colonize alternative herbaceous hosts (Pérez-Jiménez, 2006; Schena et al., 2008). Economic feasibility, impact on the natural environment and the effectiveness of control strategies vary from preventive to curative approaches, and from intervening in the nursery or in the field. Sensitive molecular diagnostic tools, biocontrol agents and proper interventions in the nursery all help in a successful control strategy (Schena et al., 2002; Schena \& Ippolito, 2003; Schena et al., 2008; Pasini et al., 2016).

However, farmers frequently have to manage the rapid spread of the disease in different species. Systemic products - fungicides and resistance inducers - might the plant replicates, while in the other treatments viability was kept with normal vegetative conditions throughout the trial period. Statistical significances were obtained by MANOVA-Hotelling pairwise comparisons (for standard deviations and errors, see Online Resources 7)

work well to protect plants that are still unaffected in an olive grove that is being impacted by an epidemic.

We compared an innovative copper-based product, Dentamet, which has been reported to protect olive trees against OQDS (Scortichini et al., 2018; Tatulli et al., 2021), and three phosphite-based products, with traditional fungicides that are highly effective against phytopathogenic fungi but can impact the environment and food safety.

All tested products strongly inhibited the growth of D. necatrix in vitro, and Propiconazole and Thiophanate methyl devitalized the fungus. Surely fungistatic and fungicidal effects depend on dosage of each product, but we inferred dosages from the permitted concentration ranges reported in the labels of the products (Table 3).

We then choose three of them to test in a treatmentand-inoculationin planta assay. Only Thiophanate methyl applied with a preventive modality, at $0.5 \mathrm{~g} / \mathrm{Lt}$ both as spray on the foliage and as soil drenching, fully protected the inoculated plants. In addition to maintaining the maximum cumulative survival probability throughout the trial, all survivors showed an optimal vegetative condition, which was indistinguishable from that of non-inoculated plants. Importantly, the inoculation wounds were completely healed, and were free from any canker lesion and pathogen colonization. The control of Dematophora root rot' in avocado using Thiophanate methyl has been previously reported 

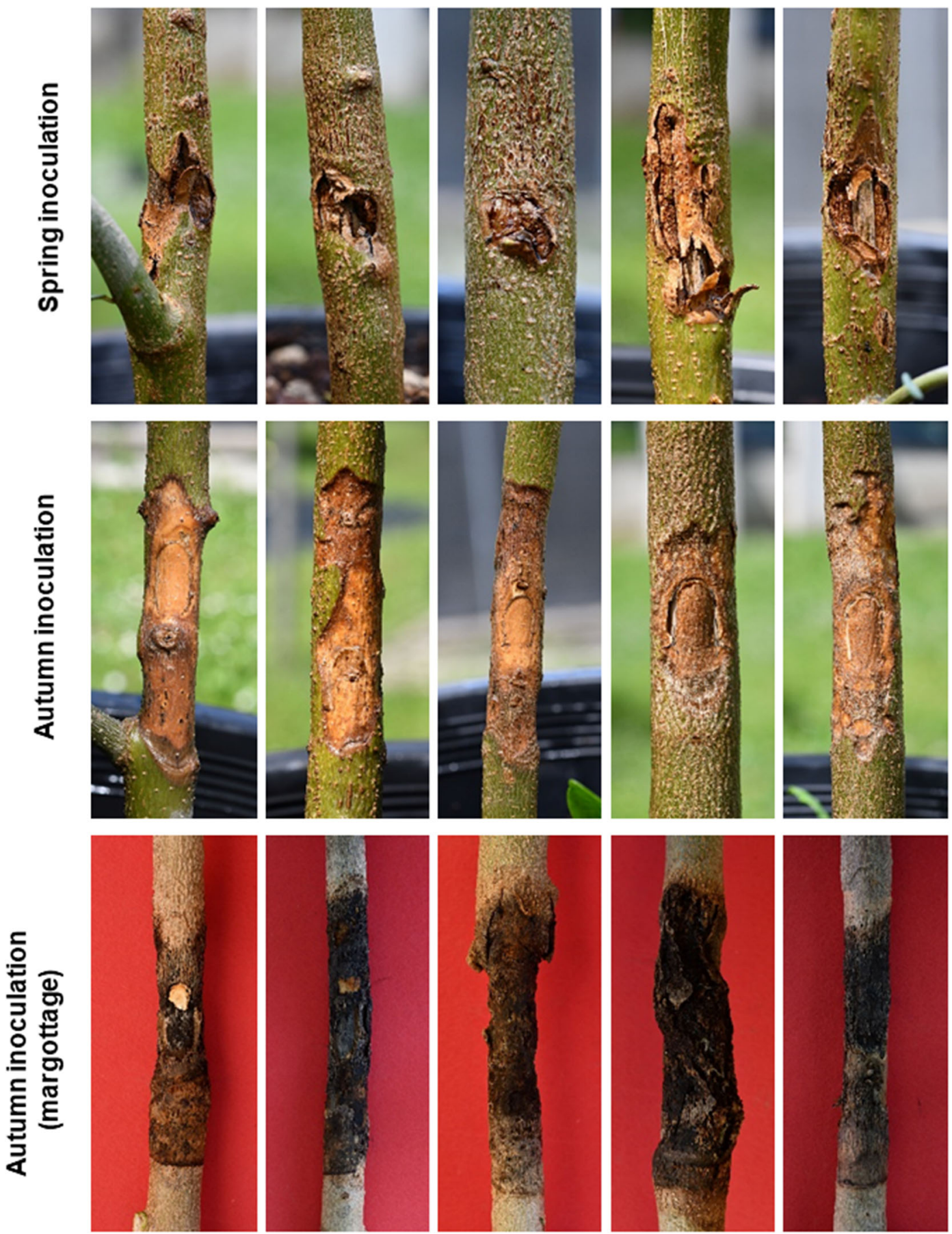

Fig. 10 Outcome of inoculation with Dematophora necatrix on Leccino' plants in different seasons and a comparison with marcottage inoculation method. Canker lesions obtained with the

autumn inoculation were much more severe than those from the spring inoculation. Moreover, they were destructive when marcottage was applied at the inoculation point

(López-Herrera \& Zea-Bonilla2007). Our results confirm that preventive strategies are the best to obtain acceptable results (Schena et al., 2008; Pasini et al., 2016). 


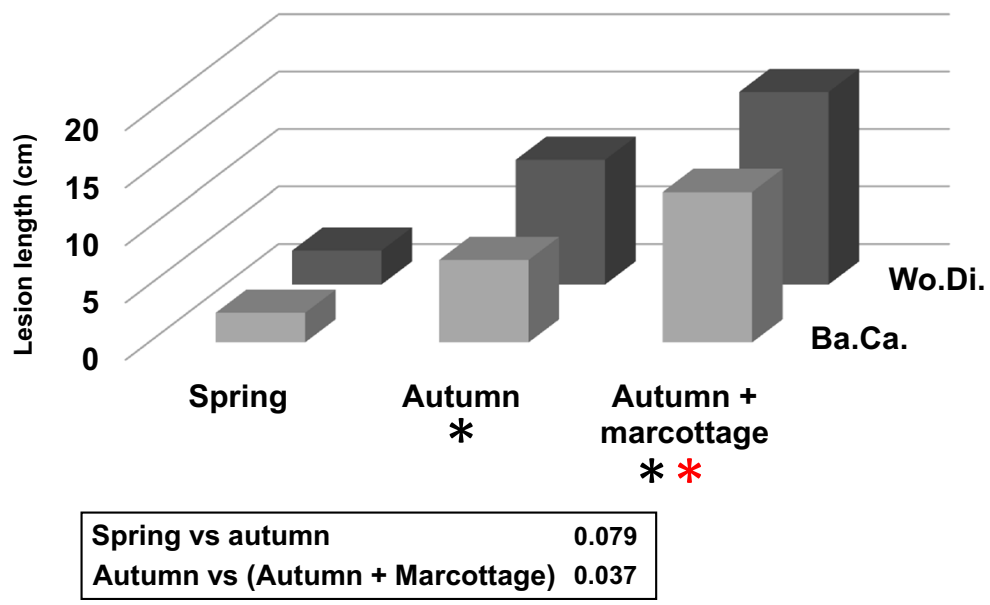

Fig. 11 Length of tissue necrosis - bark canker (Ba.Ca.) and wood discolouration (Wo.Di.) - caused by Dematophora necatrix on Leccino' plants inoculated in different seasons and (not) subjected to marcottage. The red asterisk indicates that the treatment led to the loss of viability of two plant replicates (out of five). The black asterisk indicates that all plant replicates underwent

In 2020 the European Commission did not renew the approval of Tiophanate methyl though without preventing the submission of a further application for this fungicide (European Commission 2020). Hence, to the present day, the finding that Tiophanate methyl has strong capacity to control Dematophora root rot' of olive tree has exclusively an experimental value in the countries of European Union (EU). defoliation throughout the trial period reaching $40-95 \%$ at the moment of the final recording. In the spring treatment, viability was kept with normal vegetative conditions in all replicates. Statistical significances were obtained by MANOVA-Hotelling pairwise comparisons (for standard deviations and errors, see Online Resources 7)

In fact, the use of Thiophanate methyl (and other pesticides) with nanoparticle (NP)-based technology is currently being investigated. NPs increase the effectiveness of active substances by enhancing drug bioavailability and delivery within the plant, while strongly reducing the application dose (Malandrakis et al., 2020a). For example, Thiophanate methyl in combination with $\mathrm{Ag}$ and $\mathrm{Cu}-\mathrm{NP}$ has been shown to facilitate an

Table 5 Effects of culturing Dematophora necatrix on solid and liquid media (PDB and water), supplemented with (potential) fungicides

\begin{tabular}{lllll}
\hline Isolates of Dematophora necatrix & \multicolumn{2}{l}{ CREA-DC TPR OL.82 ${ }^{1}$} & & \multicolumn{2}{c}{ CREA-DC TPR OL.89 ${ }^{1,2}$} \\
\cline { 2 - 4 } Agrochemicals & Solid & & Solid \\
\hline Dentamet & Gr.inhib. (100) & $\checkmark$ & Gr.inhib. (100) \\
Al-phosphite & Gr.inhib. (100) & $\checkmark$ & Gr.inhib. (100) \\
K-phosphite & Gr.inhib. (79) & $\checkmark$ & Gr.inhib. (85) \\
Si-phosphite & Gr.inhib. (92) & $\checkmark$ & Gr.inhib. (100) \\
Tebuconazole & Gr.inhib. (100) & $\checkmark$ & Gr.inhib. (91) & N.P. \\
Propiconazole & Biocidal & $\checkmark$ & Biocidal & N.P. \\
Thiophanate methyl & Biocidal & $\checkmark$ & Biocidal & N.P. \\
\hline
\end{tabular}

${ }^{1}$ Gr. Inhib. = Growth inhibition; $\checkmark=$ confirm results obtained on solid medium

Growth inhibition is considered as the complete block of growth or a reduced mycelial growth compared with controls non supplemented with the products

In brackets the percentage growth reduction of fungal species on PDA supplemented with the products compared with their growth on nonsupplemented PDA. Hence 100 means a $100 \%$ growth inhibition compared to growth in the non-supplemented medium, i.e. a complete block of the growth. ${ }^{2}$ N.P. $=$ not performed 


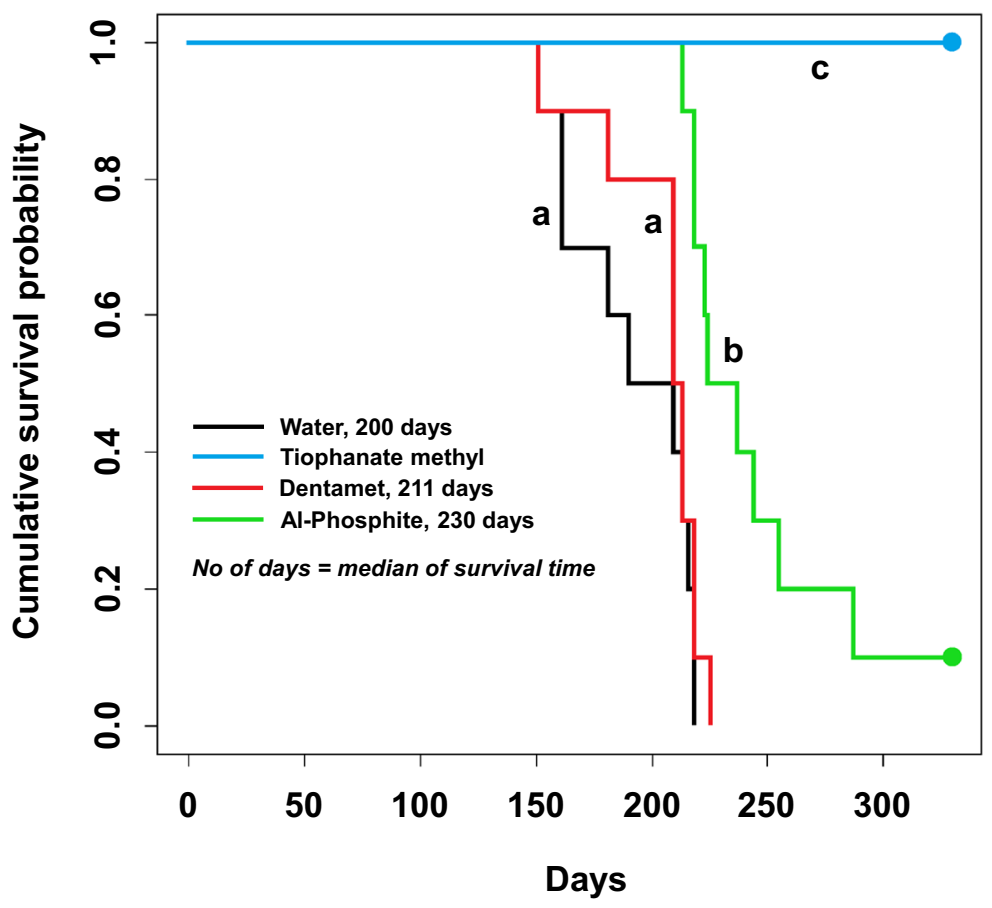

Fig. 12 Survival curves of the treatment-and-inoculation preventive trial according to the Kaplan-Meier estimate. The curves show the survival pattern of plants treated with the different (potential) fungicide and with water (as a control) and inoculated with Dematophora necatrix. All plants treated with the products and inoculated with PDA survived in optimal vegetative conditions throughout the trial (not shown in the figure). Different letters

additive and synergistic effect in the in vitro/in vivo inhibition of phytopathogenic fungi, Monilia fructicola and Botrytis cynerea, together with a reduction in doses (Malandrakis et al., 2020a; Malandrakis et al., 2020b). Specifically, the latter authors obtained a high level of $M$. fructicola inhibition both in vitro and in vivo using $1 / 50$ of the maximum recommended dose of Thiophanate methyl. In addition, synergistic inhibitive effects were also obtained against fungal strains resistant to this fungicide (Malandrakis et al., 2020a). Consequently NP-based-technologies could enhance the inhibitive capacity of the fungicides and other active substances, thus also giving a chance to those products that exerted an in vitro inhibition on the fungus, but which failed the in vivo control in our study, i.e., Dentamet and Al-phosphite (Baldassarre et al., 2020). Our study regarding the in vitro inhibition of $D$. necatrix and in planta control of Dematophora root rot', is thus a first step at optimizing the antifungal activity of the fungicides and other active substances, while reducing doses. indicate statistically significant differences among the curves calculated with log rank test. Censoring is indicated by a dot. Alphosphite vs water $\mathrm{p}=1 \mathrm{e}-04$, Thiophanate methyl vs water $\mathrm{p}=$ 4e-06, Al-phosphite vs Dentamet $\mathrm{p}=0.001$, Thiophanate methyl vs Dentamet $\mathrm{p}=4 \mathrm{e}-06$, Thiophanate methyl vs Al-phosphite $\mathrm{p}=$ $4 \mathrm{e}-05$

Developing NP-based protocols for Tiophanate methyl would be a good starting point for a future reconsideration of the fungicide by the European Commission, being possible to submit a further application for thiophanate methyl pursuant to Article 7 of Regulation (EC) No 1107/2009 (European Commission 2020). This would be the way forward not only for EU but also for non-EU countries where Thiophanate methyl is approved in order to reconcile the high fungicidal power with the necessity to safeguard the environment, food and human health.

It is worth mentioning that diseases such as brown rot (caused by M. fructicola) and grey mould (caused by $B$. cynerea) each year require periodic interventions in the field - with the consequent massive bioaccumulation of pesticides and risk for selecting resistant fungal strains - as they are ubiquitous aerial-transmitted diseases. This is not the case of Dematophora root rot', which is not a seasonal disease. In fact, a severe manifestation such as the one we report here is rare, albeit destructive. When it appears, chemical applications 
should be considered as emergency interventions aimed at saving the trees. The timely removal of symptomatic plants including their debris underground and soil solarization - the latter limited to extensive/intensive plantings - should also be integrated, thus increasing the effectiveness of the control strategy.

Favolosa' is planted throughout Apulia due to its resistance to OQDS, which destroyed several olive groves (Boscia et al., 2017). At the same time D. necatrix affects several tree species in Apulia (Carlucci et al., 2013b) and in this work we clearly showed that Favolosa' can succumb to D. necatrix, especially in the phase of arboretum constitution. Finding an additional effective control measure is thus particularly important.

In this study we report the presence of E. lacerata in olive trees in both the necrotic tissue colonized by $D$. necatrix and the healthy-looking wood of apparently healthy saplings. Overall, to the best of our knowledge, there have been no previous reports of E. lacerata in Italy, and worldwide in olive trees.

We have clearly shown that $D$. necatrix is the agent of the disease observed in olive trees. However, the presence of E. lacerata in olive trees is also of interest. Emmia lacerata is a polypore species belonging to the Irpicaceae Spirin \& Zmitr. within the Polyporales Gäum. (Justo et al., 2017; Chen et al., 2020) and occurs on both gymnosperms and angiosperms as an agent of white rot. It is widespread in northeast Asia, where it was described as a new species with the name Ceriporia lacerata(Suhara, 2003) from a ripe basidiocarp developed in a culture isolated from a white-rotted tree on Kyushu Island, Japan. It was then reported, with the same name, in China (Cui et al., 2006; Jia et al., 2014), Korea (Jang et al., 2012) and in Indonesia (Wulandari et al., 2018). In their phylogenetic study, Floudas and Hibbett (2015) also included a voucher specimen of Ceriporia (Emmia) lacerata (FP-55521T) recovered from a dead Ulmus in Lousiana, United States (see Acc. Nos. KP135024 and KP135202 in the NCBI).

The specific nature of the Asiatic specimens coincides with a number of specimens from Russia and the USA which were known for more than a century with different names, such as Polyporus latemarginatus Durieu et Mont. (1856), and Oxyporus latemarginatus (Durieu et Mont.) Donk (1966). On this basis, Zmitrovich and colleagues founded a new genus Emmia Zmitr., Spirin et Malysheva - as a result of their morphological/molecular taxonomic reassessment and transferred these differently named specimens to the new taxon E. latemarginata (Durieu et Mont.) Zmitr., Spirin. et Malysheva (Zmitrovich et al., 2006; Zmitrovich \& Malysheva, 2014).

The most recent step in this taxonomic reassessment was the foundation of the species E. lacerata to which all Russian, American, and Asiatic isolates of C. lacerata and E. latemarginata have been transferred (Wu et al., 2017). However, a direct comparison between Asiatic and Russian isolates was still lacking.

The topology of our phylogenetic tree is very close to that of Chen et al. (2020) thus aligning our results to the current state of the art of the Irpicaceae taxonomy. In our phylogenetic analysis, isolates from olive trees grouped with maximum statistical support with known voucher specimens of Emmia (Ceriporia) lacerata from Asia and the United States and E. latemarginata from Russia. The grouping of Asiatic, Russian and American isolates in the same phylogenetic clade, including also the Italian isolates from olive characterized in this study, clearly confirms that $E$. (ex Ceriporia) lacerata and $E$. latemarginata refer to the same taxon. Interestingly in our phylogeny, in the E. lacerata clade, there is a slight distinction between Asiatic specimens and those from Russia, USA and Italy, suggesting an intraspecific variability or the possible existence of sub-specific cryptic taxa within E. lacerata, which thus needs further investigation. Interestingly, this phylogenetic distinction was confirmed by the basidiospore size of our isolates which was closer to that of the Russian isolates than to the Asian ones, which were smaller (Online Resource 10).

Ceriporia cystidiata was included in the E. lacerata group, similarly to the phylogeny of Permpornsakul et al. (2016) and Chen et al. (2020). However, isolates from olive trees were nearest to E. lacerata from Lousiana (FP-55521-T) and the Russian specimens with nucleotide identity among concatenated sequences of $100 \%$ in most cases. Moreover, basidiospore of C. cystidiata are allantoid and much longer-shaped (Permpornsakul et al. 2016, Online Resource 10), which once again rules out any identification of the olive tree isolates with $C$. cystidiata.

The role of E. lacerata in the D. necatrix-olive tree pathosystem remains obscure. The inoculation trial showed the capacity of E. lacerata to infect healthy olive trees through the wounds and to survive in the xylem of the tree without causing visible alterations. It is well known that some microbial species can live inside 
the host plant ranging from an endophytic lifestyle to a marked saprotrophic or pathogenic lifestyle, to which they revert after the host loses its viability or is subjected to some biotic/abiotic stress. Interestingly, any members of the Phlebioid clade live as endophytes in living trees (Martin et al., 2015), or as saprotrophs causing white rot on dead woody substrates (Ryvarden \& Melo, 2017).

Emmia lacerata is currently being considered for bioremediation and for environmental-friendly treatment in the supply chain to convert woody biomass into fuel ethanol. In fact, as a white rot agent it has both cellulase and phenol oxidase activity (Lee et al., 2007; Al-Hawash et al., 2020; Nguyen et al., 2021). We thus hypothesize that E. lacerata likely survives latently within olive trees with possible hidden roles and its saprotrophic wood-decaying potential exploits the rotting activity of $D$. necatrix and possibly other severe stresses. In a natural environment in which a continuous recycling of the elements perpetuates between living and non-living, organic, and inorganic components, this strategy would be an optimization of the decomposition processes that take place in organisms approaching death. The same hypothesis could also apply to the other Basidiomycota taxa here occasionally detected in the diseased olive trees: Phlebia acerina, Trametes versicolor and Porostereum spadiceum, which we decided not to investigate further in this work.

Supplementary Information The online version contains supplementary material available at https://doi.org/10.1007/s10658022-02458-1.

Acknowledgements This research was supported by a Mipaaf (the Italian Ministry of Agricultural and Forestry Policies) project "SALVAOLIVI, Salvaguardia e Valorizzazione del patrimonio Olivicolo Italiano con azioni di ricerca nel settore della difesa fitosanitaria - DM 33437, 21/12/2017'. A special thanks to Dr. Francesco Faggioli, coordinator of the project and plant manager of our Research Center of Rome, whose excellent work during the Covid-19 pandemic, ultimately enabled the development of this research.

Code availability (software application or custom code) Not applicable.

Data availability Raw data can be viewed upon request.Supplementary Information The online version contains supplementary material available at https://doi.org/10.1007 /s10658-022-02458-1.

\section{Declarations}

Conflicts of interest/competing interests The authors have no conflict of interest or competing interests to declare.
Ethics approval All principles of ethical and professional conduct have been followed during this research and the drafting of this manuscript.

Consent to participate All the authors have given consent to participate in the authorship.

Consent for publication All the authors agree with the content of the article and gave explicit consent to submit and publish the article.

\section{References}

Al-Hawash, A. B., Al-Qurnawi, W. S., Abbood, H. A., Hillo, N. A., Ghalib, H. B., Zhang, X., \& Ma, F. (2020). Pyrenedegrading fungus Ceriporia lacerata RF-7 from contaminated soil in Iraq. Polycyclic Aromatic Compounds, 1-9. https://doi.org/10.1080/10406638.2020.1713183

Anselmi, N., \& Giorcelli, A. (1990). Factors influencing the incidence of Rosellinia necatrix Prill. in poplars. Forest Pathology, 20(3), 175-183. https://doi.org/10.1111/j.14390329.1990.tb01128.x

Baldassarre, F., Tatulli, G., Vergaro, V., Mariano, S., Scala, V., Nobile, C., Pucci, N., Dini, L., Loreti, S., \& Ciccarella, G. (2020). Sonication-Assisted Production of Fosetyl-Al Nanocrystals: Investigation of Human Toxicity and In Vitro Antibacterial Efficacy against Xylella fastidiosa. Nanomaterials, 10(6), 1174, 1-20. https://doi.org/10.3390 /nano10061174

Besnard, G., Khadari, B., Navascués, M., Fernández-Mazuecos, M., El Bakkali, A., Arrigo, N., Baali-Cherif, D., BruniniBronzini de Caraffa, V., Santoni, S., Vargas, P., \& Savolainen, V. (2013). The complex history of the olive tree: From late quaternary diversification of Mediterranean lineages to primary domestication in the northern Levant. Proceedings of the Royal Society B, 280(20122833), 1-7. https://doi.org/10.1098/rspb.2012.2833

Bewick, V., Cheek, L., \& Ball, J. (2004). Statistics review 12: Survival analysis. Critical Care, 8(5), 1-6.

Bilodeau, G. J., Koike, S. T., Uribe, P., \& Martin, F. N. (2012). Development of an assay for rapid detection and quantification of Verticillium dahliae in soil. Phytopathology, 102(3), 331-342. https://doi.org/10.1094/PHYTO-05-11-0130

Boscia, D., Altamura, G., Ciniero, A., Di Carolo, M., Dongiovanni, C., Fumarola, G., Giampetruzzi, A., Greco, P., La Notte, P., Loconsole, G., Manni, F., Melcarne, G., Montilon, V., Morelli, M., Murrone, N., Palmisano, F., Pollastro, P., Potere, O., Roseti, V., et al. (2017). Resistenza a Xylella fastidiosa in diverse cultivar di olivo. L'Informatore Agrario, 11, 59-63. https://doi.org/10.5281/zenodo.495708

Carlucci, A., Raimondo, M. L., Cibelli, F., Phillips, A. J., \& Lops, F. (2013a). Pleurostomophora richardsiae, Neofusicoccum parvum and Phaeoacremonium aleophilum associated with a decline of olives in southern Italy. Phytopathologia Mediterranea, 517-527. https://doi.org/10.14601 /Phytopathol_Mediterr-13526 
Carlucci, A., Manici, L. M., Colatruglio, L., Caputo, A., \& Frisullo, S. (2013b). Rosellinia necatrix attack according to soil features in the Mediterranean environment. Forest Pathology, 43(1), 12-18. https://doi.org/10.1111/j.14390329.2012.00787.x

Carlucci, A., Lops, F., Cibelli, F., \& Raimondo, M. L. (2015). Phaeoacremonium species associated with olive wilt and decline in southern Italy. European Journal of Plant Pathology, 141(4), 717-729. https://doi.org/10.1007 /s10658-014-0573-8

Chen, C. C., Chen, C. Y., Lim, Y. W., \& Wu, S. H. (2020). Phylogeny and taxonomy of Ceriporia and other related taxa and description of three new species. Mycologia, 112(1), 64 82. https://doi.org/10.1080/00275514.2019.1664097

Cui, B., Wei, Y., \& Dai, Y. (2006). Polypores from Zijin mountain, Jiangsu province. Mycosystema, 25(1), 9-14.

Díez, C. M., Moral, J., Cabello, D., Morello, P., Rallo, L., \& Barranco, D. (2016). Cultivar and tree density as key factors in the long-term performance of super high-density olive orchards. Frontiers in Plant Science, 7(1226), 1-13.

European Commission. (2020, October 15). Commission implementing regulation (EU) 2020/1498 of 15 October 2020, from EUR-Lex - 32020R1498 - EN - EUR-Lex (europa.eu).

European Commission. (2021, July 29). Market situation in the olive oil and table olives sectors - production, Consumption and ending stocks, from market-situation-olive-oil-tableolives_en.pdf (europa.eu).

Faretra, F., \& Frisullo, S. (2002). Rosellinia (Dematophora) root rot. In B. I. Teviotdale, T. J. Michailides, \& J. W. Pscheidt (Eds.), Compendium of nut crop diseases temperate zones (pp. 6-7). APS Press. https://doi.org/10.1111/j.14390329.2012.00787.x

Farinelli, D., \& Tombesi, S. (2015). Performance and oil quality of 'Arbequina' and four Italian olive cultivars under super high density hedgerow planting system cultivated in Central Italy. Scientia Horticulturae, 192, 97-107. https://doi.org/10.1016 /j.scienta.2015.04.035

Figueres, F. G., \& Grouard, B. C. (2001). Incidencia de Dematophora necatrix en olivo. Fruticultura Profesional, 120, 51-54.

Floudas, D., \& Hibbett, D. S. (2015). Revisiting the taxonomy of Phanerochaete (Polyporales, Basidiomycota) using a four gene dataset and extensive ITS sampling. Fungal Biology, 119(8), 679-719. https://doi.org/10.1016/j. funbio.2015.04.003

Fontanazza, G., Bartolozzi, F., \& Vergari, G. (1998). Fs-17. Rivista di Frutticoltura, 5, 61.

Frisullo, S., Camele, I., Agosteo, G. E., Boscia, D., \& Martelli, G. P. (2014). Brief historical account of olive leaf scorch ("brusca") in the Salento peninsula of Italy and state-of-theart of the olive quick decline syndrome. Journal of Plant Pathology, 96(3), 441-449. https://doi.org/10.4454/JPP.V96 I3.009

Goel, M. K., Khanna, P., \& Kishore, J. (2010). Understanding survival analysis: Kaplan-Meier estimate. International Journal of Ayurveda Research, 1(4), 274-278. https://doi. org/10.4103/0974-7788.76794

Guillaumin, J. J., Mercier, S., \& Dubos, B. (1982). Les pourridies a Armillariella et Rosellinia en France sur vigne, arbres fruitiers et cultures florales. I.-Etiologie et symptomatologie.
Agronomie, 2(1), 71-80. https://doi.org/10.1051 /agro: 19820110

Hammer, Ø., Harper, D. A. T., \& Ryan, P. D. (2001). PAST: Paleontological statistics software package for education and data analysis. Palaeontologia Electronica, 4(1), 1-9.

Harper, S. J., Ward, L. I., \& Clover, G. R. G. (2010). Development of LAMP and real-time PCR methods for the rapid detection of Xylella fastidiosa for quarantine and field applications. Phytopathology, 100, 1282-1288. https://doi.org/10.1094 /PHYTO-06-10-0168

Jang, Y., Choi, H. E., Lim, Y. W., Lee, J. S., \& Kim, J. J. (2012). The first report of Ceriporia lacerata (Phanerochaetaceae, Basidiomycota) in Korea. Mycotaxon, 119(1), 397-403. https://doi.org/10.5248/119.397

Jeger, M., Caffier, D., Candresse, T., Chatzivassiliou, E., DehnenSchmutz, K., Gilioli, G., Gregoire, J.-C., Miret, J. A. J., MacLeod, A., Navajas Navarro, M., Niere, B., Parnell, S., Potting, R., Rafoss, T., Rossi, V., Urek, G., Van Bruggen, A., Van der Werf, W., West, J., et al. (2018). Updated pest categorisation of Xylella fastidiosa. EFSA Journal, 16(7), 5357, 1-61. https://doi.org/10.2903/j.efsa.2018.5357

Jia, B. S., Zhou, L. W., Cui, B. K., Rivoire, B., \& Dai, Y. C. (2014). Taxonomy and phylogeny of Ceriporia (Polyporales, Basidiomycota) with an emphasis of Chinese collections. Mycological Progress, 13, 81-93. https://doi.org/10.1007 /s11557-013-0895-5

Jimenez-Diaz, R. M., Cirulli, M., Bubici, G., del Mar JimenezGasco, M., Antoniou, P. P., \& Tjamos, E. C. (2012). Verticillium wilt, a major threat to olive production: Current status and future prospects for its management. Plant Disease, 96(3), 304-329. https://doi.org/10.1094 /PDIS-06-11-0496

Justo, A., Miettinen, O., Floudas, D., Ortiz-Santana, B., Sjökvist, E., Lindner, D., Nakasone, K., Niemelä, T., Larsson, K. H., \& Ryvarden, L. (2017). A revised family-level classification of the Polyporales (Basidiomycota). Fungal Biology, 121(9), 798-824. https://doi.org/10.1016/j.funbio.2017.05.010

Kaplan, E. L., \& Meier, P. (1958). Nonparametric estimation from incomplete observations. Journal of the American Statistical Association, 53(282), 457-481. https://doi.org/10.2307 12281868

Kumar, S., Stecher, G., Li, M., Knyaz, C., \& Tamura, K. (2018). MEGA X: Molecular evolutionary genetics analysis across computing platforms. Molecular Biology and Evolution, 35(6), 1547-1549. https://doi.org/10.1093/molbev/msy096

Lee, J. W., Gwak, K. S., Park, J. Y., Park, M. J., Choi, D. H., Kwon, M., \& Choi, I. G. (2007). Biological pretreatment of softwood Pinus densiflora by three white rot fungi. Journal of Microbiology, 45(6), 485-491.

Lo Giudice, V., Raudino, F., Magnano di San Lio, R., Cacciola, S. O., Faedda, R., \& Pane, A. (2010). First report of a decline and wilt of young olive trees caused by simultaneous infections of Verticillium dahliae and Phytophthora palmivora in Sicily. Plant Disease, 94(11), 1372. https://doi.org/10.1094 /PDIS-07-10-0480

López-Escudero, F. J., \& Mercado-Blanco, J. (2011). Verticillium wilt of olive: A case study to implement an integrated strategy to control a soil-borne pathogen. Plant and Soil, 344(1), 1-50. https://doi.org/10.1007/s11104-010-0629-2

López-Herrera, C. J., \& Zea-Bonilla, T. (2007). Effects of benomyl, carbendazim, fluazinam and thiophanate methyl on 
white root rot of avocado. Crop Protection, 26(8), 11861192. https://doi.org/10.1016/j.cropro.2006.10.015

Mairech, H., López-Bernal, Á., Moriondo, M., Dibari, C., Regni, L., Proietti, P., Villalobos, F. J., \& Testi, L. (2020). Is new olive farming sustainable? A spatial comparison of productive and environmental performances between traditional and new olive orchards with the model OliveCan. Agricultural Systems, 181(102816), 1-14. https://doi.org/10.1016/j. agsy.2020.102816

Malandrakis, A. A., Kavroulakis, N., \& Chrysikopoulos, C. V. (2020a). Use of silver nanoparticles to counter fungicideresistance in Monilinia fructicola. Science of the Total Environment, 747(141287), 1-12. https://doi.org/10.1016/j. scitotenv.2020.141287

Malandrakis, A. A., Kavroulakis, N., \& Chrysikopoulos, C. V. (2020b). Synergy between cu-NPs and fungicides against Botrytis cinerea. Science of the Total Environment, 703, 135557. https://doi.org/10.1016/j.scitotenv.2019.135557

Mantel, N. (1966). Evaluation of survival data and two new rank order statistics arising in its consideration. Cancer Chemotherapy Reports, 50(3), 163-170.

Martin, R., Gazis, R., Skaltsas, D., Chaverri, P., \& Hibbett, D. (2015). Unexpected diversity of basidiomycetous endophytes in sapwood and leaves of Hevea. Mycologia, 107(2), 284-297. https://doi.org/10.3852/14-206

Melzer, V. (1924). L'ornementation des spores de Russules. Bulletin Trimestriel de la Societe Mycologique de France, $40,78-81$.

Moral, J., Agustí-Brisach, C., Pérez-Rodríguez, M., Xaviér, C., Raya, M. C., Rhouma, A., \& Trapero, A. (2017). Identification of fungal species associated with branch dieback of olive and resistance of table cultivars to Neofusicoccum mediterraneum and Botryosphaeria dothidea. Plant Disease, 101(2), 306-316. https://doi. org/10.1094/PDIS-06-16-0806-RE

Nei, M., \& Kumar, S. (2000). Molecular evolution and phylogenetics. Oxford University Press.

Nguyen, M. H., Kim, D. H., Park, J. H., Park, Y. U., Lee, M. Y., Choi, M. H., Lee, D. H., \& Lee, J. K. (2021). Identification, enzymatic activity, and decay ability of Basidiomycetous Fungi isolated from the decayed bark of Mongolian oak (Quercus mongolica Fisch. Ex Ledeb.). Journal of Forest and Environmental Science, 37(1), 52-61. https://doi. org/10.7747/JFES.2021.37.1.52

OEPP/EPPO. (2019). PM 7/24 (4). Xylella fastidiosa. OEPP/ EPPO Bulletin, 49, 175-227.

Özcan, M. M., \& Matthäus, B. (2017). A review: Benefit and bioactive properties of olive (Olea europaea L.) leaves. European Food Research and Technology, 243(1), 89-99. https://doi.org/10.1007/s00217-016-2726-9

Pasini, L., Prodorutti, D., Pastorelli, S., \& Pertot, I. (2016). Genetic diversity and biocontrol of Rosellinia necatrix infecting apple in northern Italy. Plant Disease, 100(2), 444-452. https://doi. org/10.1094/PDIS-04-15-0480-RE

Pérez-Jiménez, R. M. (2006). A review of the biology and pathogenicity of Rosellinia necatrix-the cause of white root rot disease of fruit trees and other plants. Journal of Phytopathology, 154(5), 257-266. https://doi.org/10.1111 j.1439-0434.2006.01101.x

Permpornsakul, P., Prasongsuk, S., Lotrakul, P., Eveleigh, D. E., Kobayashi, D. Y., Wu, S. H., Imai, T., \& Punnapayak, H.
(2016). Two new records of the resupinate polypore fungi, Ceriporia cystidiata and Macrohyporia dictyopora, in Thailand. ScienceAsia, 42(3), 171-177. https://doi. org/10.2306/scienceasia1513-1874.2016.42.171

Peto, R., \& Peto, J. (1972). Asymptotically efficient rank invariant test procedures. Journal of the Royal Statistical Society: Series A (General), 135(2), 185-207. https://doi. org/10.2307/2344317

Petrini, L. E. (2013). Rosellinia - a world monograph. Bibliotheca Mycologica, 205. Stuttgart: J. Cramer in der Gebrüder Borntraeger Verlagsbuchhandlung. ISBN 9783443591076

Pliego, C., Lopez-Herrera, C., Ramos, C., \& Cazorla, F. M. (2012). Developing tools to unravel the biological secrets of Rosellinia necatrix, an emergent threat to woody crops. Molecular Plant Pathology, 13(3), 226-239. https://doi. org/10.1111/J.1364-3703.2011.00753.X

R Core Team. (2021). R: A language and environment for statistical computing. R Foundation for Statistical Computing, Vienna, Austria. https://www.R-project.org/

Rich, J. T., Neely, J. G., Paniello, R. C., Voelker, C. C., Nussenbaum, B., \& Wang, E. W. (2010). A practical guide to understanding Kaplan-Meier curves. Otolaryngology and Head and Neck Surgery, 143(3), 331-336. https://doi. org/10.1016/j.otohns.2010.05.007

Rigacci, S., \& Stefani, M. (2016). Nutraceutical properties of olive oil polyphenols. An itinerary from cultured cells through animal models to humans. International Journal of Molecular Sciences, 17(6), 843. https://doi.org/10.3390 /ijms17060843

Roca, L. F., Romero, J., Raya, M. C., \& Trapero, A. (2016). Decaimiento y muerte de olivos por Rosellinia necatrix en el Alentejo portugués. In: XVIII Congreso de la Sociedad Española de Fitopatología, 20-23 September 2016

Ryvarden, L., \& Melo, I. (2017). Poroid fungi of Europe. Series: Synopsis Fungorum, volume 37. Koeltz Botanical Books.

Sánchez Hernández, M. E., Ruiz Dávila, A., Pérez de Algaba, A., Blanco López, M. A., \& Trapero Casas, A. (1998). Occurrence of etiology of death of young olive trees southern Spain. European Journal of Plant Pathology, 104, 347-357. https://doi.org/10.1023/A:1008624929989

Schena, L., \& Ippolito, A. (2003). Rapid and sensitive detection of Rosellinia necatrix in roots and soils by real time scorpionPCR. Journal of Plant Pathology, 85(1), 15-25. https://doi. org/10.4454/jpp.v85i1.1005

Schena, L., Nigro, F., \& Ippolito, A. (2002). Identification and detection of Rosellinia necatrix by conventional and real-time scorpion-PCR. European Journal of Plant Pathology, 108(4), 355-366.

Schena, L., Nigro, F., \& Ippolito, A. (2008). Integrated management of Rosellinia necatrix root rot on fruit tree crops. In A. Ciancio \& K. G. Mukerji (Eds.), Integrated Management of Diseases Caused by Fungi, Phytoplasma and Bacteria (pp. 137-158). Springer.

Scortichini, M., Chen, J., De Caroli, M., Dalessandro, G., Pucci, N., Modesti, V., L'Aurora, A., Petriccione, M., Zampella, L., Mastrobuoni, F., Migoni, D., Del Coco, L., Girelli, C. R., Piacente, F., Cristella, N., Marangi, P., Laddomada, F., Di Cesare, M., Cesari, G., et al. (2018). A zinc, copper and citric acid biocomplex shows promise for control of Xylella fastidiosa subsp. pauca in olive trees in Apulia region 
(southern Italy). Phytopathologia Mediterranea, 57(1), 4872. https://doi.org/10.14601/Phytopathol_Mediterr-21985

Spirin, V., Vlasák, J., Rivoire, B., Kout, J., Kotiranta, H., \& Miettinen, O. (2016). Studies in the Ceriporia purpurea group (Polyporales, Basidiomycota), with notes on similar Ceriporia species. Cryptogamie Mycologie, 37(4), 421-435. https://doi.org/10.7872/crym/v37.iss4.2016.421

Stillitano, T., De Luca, A. I., Falcone, G., Spada, E., Gulisano, G., \& Strano, A. (2016). Economic profitability assessment of Mediterranean olive growing systems. Bulgarian Journal of Agricultural Science, 22(4), 517-526.

Suhara, H. (2003). A new species Ceriporia lacerata, isolated from white-rotted wood. Mycotaxon, 86, 335-347.

Tatulli, G., Modesti, V., Pucci, N., Scala, V., L'Aurora, A., Lucchesi, S., Salustri, M., Scortichini, M., \& Loreti, S. (2021). Further in vitro assessment and mid-term evaluation of control strategy of Xylella fastidiosa subsp. pauca in olive groves of Salento (Apulia, Italy). Pathogens, 10(85), 1-22. https://doi.org/10.3390/pathogens10010085

Therneau, T. M. (2021). A Package for Survival Analysis in R. R package version 3.2-11, http://CRAN.R-project. org/package=survival.

Therneau, T. M., \& Grambsch, P. M. (2000). The Cox Model. In: Modeling Survival Data: Extending the Cox Model. Statistics for Biology and Health. Springer, New York, NY. https://doi.org/10.1007/978-1-4757-3294-8_3

Úrbez-Torres, J. R., Peduto, F., Vossen, P. M., Krueger, W. H., \& Gubler, W. D. (2013). Olive twig and branch dieback: Etiology, incidence, and distribution in California. Plant Disease, 97(2), 231-244. https://doi.org/10.1094/PDIS-0412-0390-RE

Vincent, J. M. (1947). Distortion of fungal hyphae in the presence of certain inhibitors. Nature, 159(4051), 850-850.
Vitagliano, C., \& Sebastiani, L. (2003). Impianto. In P. Fiorino (Ed.), Olea - Trattato di Olivicoltura (pp. 195-209). Bologna.

Wittstein, K., Cordsmeier, A., Lambert, C., Wendt, L., Sir, E. B., Weber, J., Wurzler, N., Petrini, L. E., \& Stadler, M. (2020). Identification of Rosellinia species as producers of cyclodepsipeptide PF1022 A and resurrection of the genus Dematophora as inferred from polythetic taxonomy. Studies in Mycology, 96, 1-16. https://doi.org/10.1016/j. simyco.2020.01.001

Wu, F., Chen, J. J., Ji, X. H., Vlasák, J., \& Dai, Y. C. (2017). Phylogeny and diversity of the morphologically similar polypore genera Rigidoporus, Physisporinus, Oxyporus, and Leucophellinus. Mycologia, 109(5), 749-765. https://doi.org/10.1080/00275514.2017.1405215

Wulandari, R., Lotrakul, P., Amirta, R., Kim, S. W., Punnapayak, H., \& Prasongsuk, S. (2018). First record of Ceriporia inflata and Ceriporia lacerata (Phanerochaetaceae, Basidiomycota) from Indonesian tropical forest. Agriculture and Natural Resources, 52(5), 412-418. https://doi.org/10.1016/j. anres.2018.10.017

Yuan, Y., Ji, X. H., Wu, F., \& Chen, J. J. (2017). Ceriporia albomellea (Phanerochaetaceae, Basidiomycota), a new species from tropical China based on morphological and molecular evidences. Phytotaxa, 298(1), 20-28. https://doi. org/10.11646/phytotaxa.298.1.2

Zmitrovich, I. V., \& Malysheva, V. F. (2014). Studies on Oxyporus. I. Segregation of Emmia and general topology of phylogenetic tree. Микология и фитопатология, 48(3), 161-171.

Zmitrovich, I. V., Malysheva, V. F., \& Spirin, W. A. (2006). A new morphological arrangement of the Polyporales. I. Phanerochaetineae. Mycena: An Independent Mycological Journal, 6, 4-56. 